\title{
Parallel Operation of Inverters and Active Power Filters in Distributed Generation System: A Review
}

\author{
Shafiuzzaman Khan Khadem \\ Technological University Dublin, skkhadem@gmail.com \\ Malabika Basu \\ Technological University Dublin, mbasu@tudublin.ie \\ Michael Conlon \\ Technological University Dublin, michael.conlon@tudublin.ie
}

Follow this and additional works at: https://arrow.tudublin.ie/engscheleart2

Part of the Controls and Control Theory Commons, Electrical and Electronics Commons, and the Power and Energy Commons

\section{Recommended Citation}

Khadem, S.K. Basu, M.,Conlon, M. (2011) Parallel Operation of Inverters and Active Power Filters in Distributed Generation System: A Review. Renewable and Sustainable Energy Reviews, vol.15, 2011, pp. 5155- 5168. doi:10.1016/j.rser.2011.06.011

This Article is brought to you for free and open access by the School of Electrical and Electronic Engineering at ARROW@TU Dublin. It has been accepted for inclusion in Articles by an authorized administrator of ARROW@TU Dublin. For more information, please contact arrow.admin@tudublin.ie, aisling.coyne@tudublin.ie, gerard.connolly@tudublin.ie.

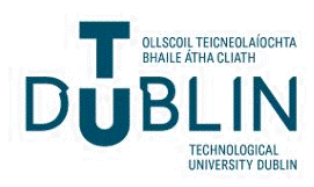




\title{
Parallel operation of inverters and active power filters in distributed generation system-A review
}

\author{
S.K. Khadem*, M. Basu, M.F. Conlon \\ School of Electrical Engineering Systems, Dublin Institute of Technology, Kevin Street, Dublin 8, Ireland
}

\section{A R T I C L E I N F O}

\section{Article history:}

Received 24 December 2010

Accepted 24 June 2011

Available online $\mathrm{xxx}$

\section{Keywords:}

Inverter

Active power filter

Parallel operation

Distributed generation

Power quality

\begin{abstract}
A B S T R A C T
In this paper a technical review of parallel operation of power electronics inverters for load sharing conditions in distributed generation (DG) network is presented. Emphasis is given to parallel operation of Active Power Filters (APFs) as they are widely used to mitigate load current disturbances into DG networks. Discussions on recent advances in control strategies as applied to APFs are presented.
\end{abstract}

(c) 2011 Elsevier Ltd. All rights reserved.

\section{Contents}

1. Introduction

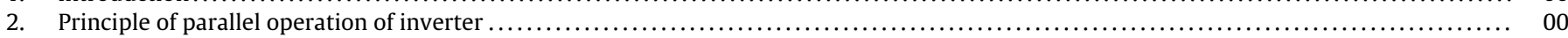

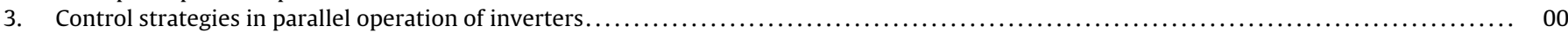

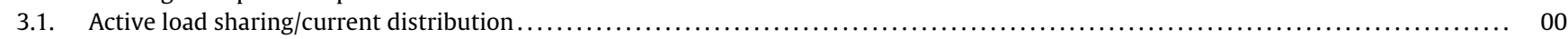

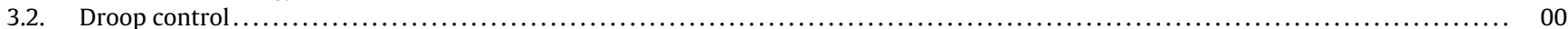

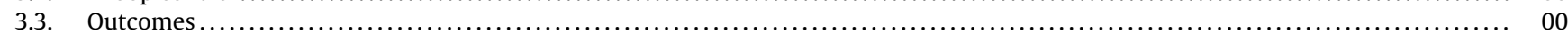

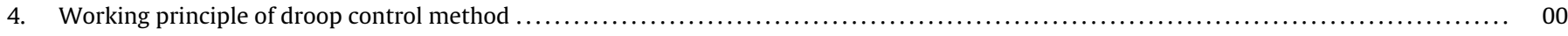

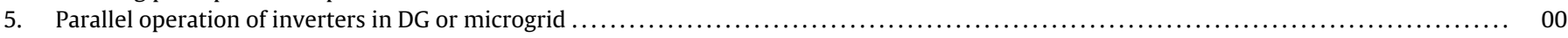

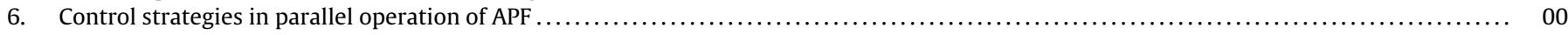

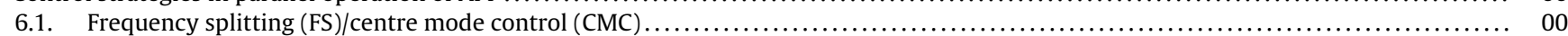

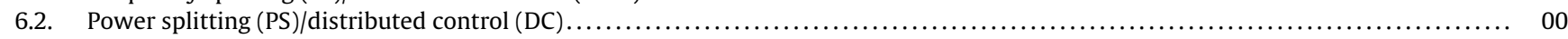

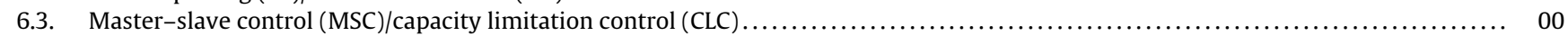

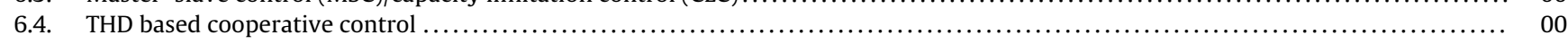

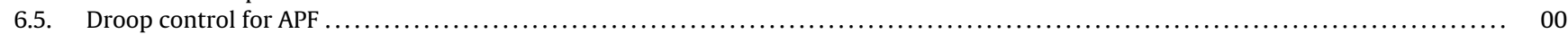

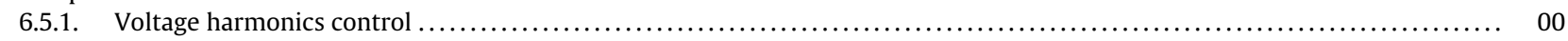

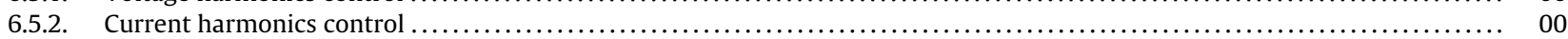

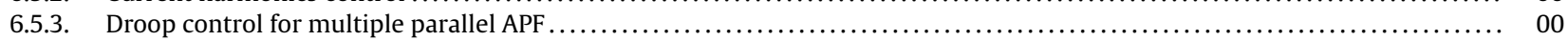

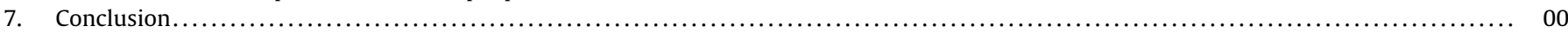

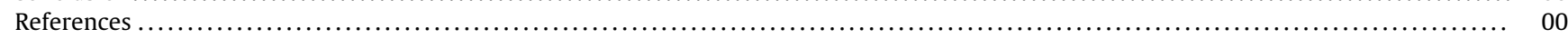

\section{Introduction}

New control, operation and management strategies are being developed to connect the increasing number of distributed

\footnotetext{
* Corresponding author. Tel.: +3531402 2814; fax: +35314024992.

E-mail addresses: skkhadem@gmail.com (S.K. Khadem), mbasu@dit.ie (M. Basu), michael.conlon@dit.ie (M.F. Conlon).
}

generation devices into the grid or microgrid in order to maintain or improve the power quality of the distribution system. Therefore, control of DG inverters is essential not only to supply the active power but also to manage of reactive power. Parallel operation of multiple inverters with low capacity has been introduced instead of the high capacity single units, to add flexibility and reliability in operation.

Increasing numbers of harmonic or sensitive loads are leading to more Active Power Filter (APF) application. Similarly, parallel

1364-0321/\$ - see front matter @ 2011 Elsevier Ltd. All rights reserved. doi:10.1016/j.rser.2011.06.011 


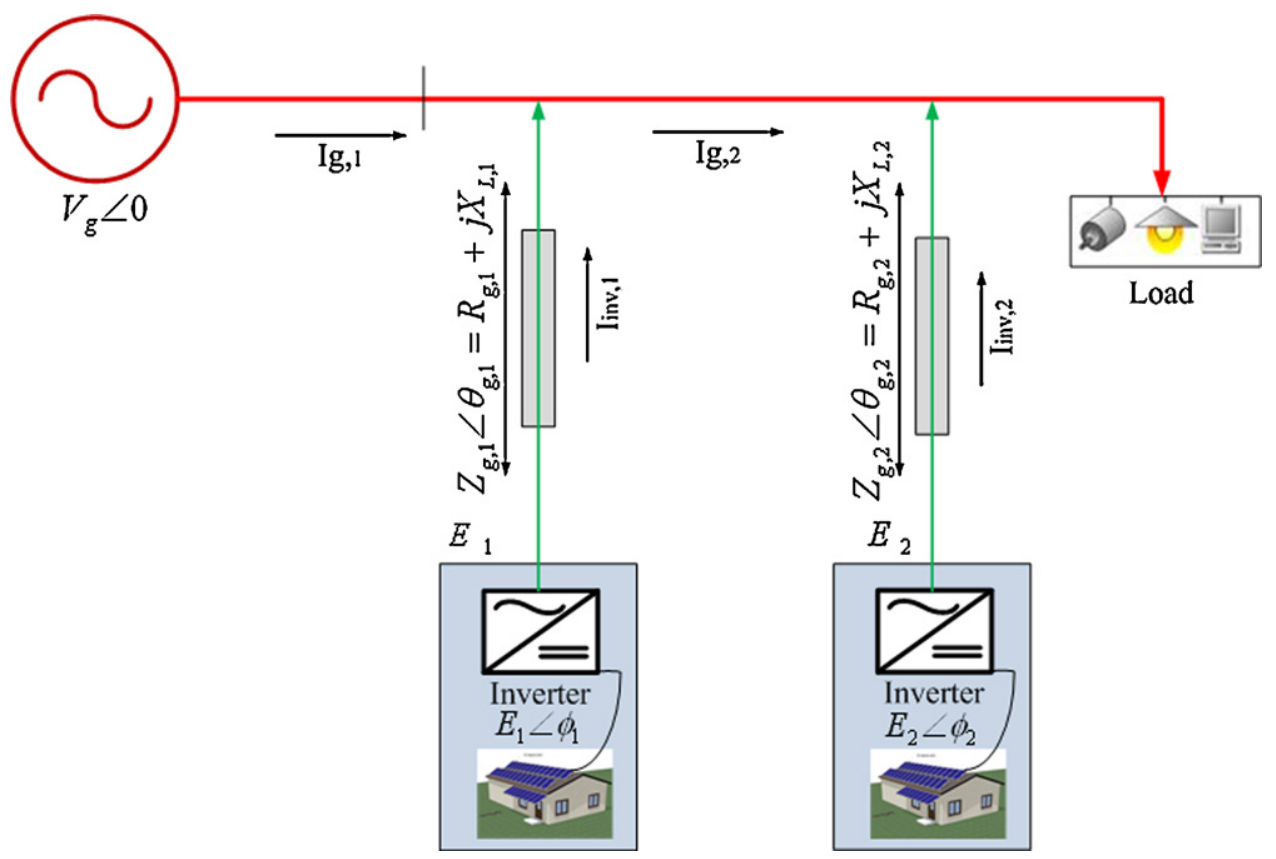

Fig. 1. Equivalent circuit of parallel inverter connected to the grid.

operation of APFs and their control strategies are being given more emphasis for compensating high levels of harmonic and reactive current in the distribution network.

In this paper, these new trends in parallel control of inverters and APFs to cope up with increasing capacity are discussed. The paper is organized as follows: In Section 2, the principle of parallel operation of inverters with their possible problems is discussed. Active load sharing and a droop control method for parallel operation of inverters is presented in brief in Section 3. It is found that droop control is very suitable for both DG and off-grid conditions. Section 4 deals with the working principle of the droop control method. Section 5 presents a discussion on the application of parallel inverters in DG or in a microgrid. Control strategies for parallel operation of APF are presented broadly in Section 6. Finally, concluding remarks are made in Section 7.

\section{Principle of parallel operation of inverter}

Balance between generated and consumed real $(P)$ and reactive $(Q)$ power indicates the stable operation of a power system. Therefore, implementing effective control over $P$ and $Q$ is very important from the operational and control points of view. The real $\left(P_{1}\right)$ and reactive $\left(Q_{1}\right)$ power transferred from the inverter to the common bus or grid can be calculated as described in [1] and from the following diagram, as shown in Fig. 1;

$P_{1}=\left[\left(\frac{E_{1} V_{g} \cos \phi_{1}}{Z_{g, 1}}-\frac{V_{g}^{2}}{Z_{g, 1}}\right) \cos \theta_{g, 1}+\frac{E_{1} V_{g}}{Z_{g, 1}} \sin \phi_{1} \sin \theta_{g, 1}\right]$

$Q_{1}=\left[\left(\frac{E_{1} V_{g} \cos \phi_{1}}{Z_{g, 1}}-\frac{V_{g}^{2}}{Z_{g, 1}}\right) \sin \theta_{g, 1}-\frac{E_{1} V_{g}}{Z_{g, 1}} \sin \phi_{1} \cos \theta_{g, 1}\right]$

Here $E_{1}$ and $V_{g}$ represent the inverter output voltage and grid voltage, respectively. For only real power transfer, $V_{g}$ and $E$ should have the same amplitude with a phase angle difference. Different amplitude of voltage with the same phase will give a reactive power circulation. When both of the magnitude and phase angle differ between the two voltage sources, it causes real and reactive power flow. Control of frequency dynamically controls the power angle and hence, the real power flow. As the output impedance of the inverter is very low, a small change in $\phi_{1}$ (phase difference between the inverter and grid voltage) could result a very large imbalance in the active power flow [2]. For parallel operation, the output voltage of all inverters must be kept strictly in phase in order to guarantee equality of the output active power for the corresponding inverters. Reactive currents can still circulate between inverters, as shown in Fig. 2, if their output voltage magnitudes differ from each other and this can overload the inverters unnecessarily.

To suppress the circulating current and prevent the dc-link overvoltage, an isolation transformer can be used as a passive control measure, as shown in Fig. 3(a) [3-5], but then the size of the transformer for high power application could be a problem. Some active methods, such as zero-sequence current control loop, coordinate control, and space vector modulation control are also described in [6-8] respectively. A simple protective control algorithm, as shown in Fig. 3(b), has also been proposed in [9] where the regeneration protection concept based on the rising dc-link voltage is considered. If $V_{d c}$ is greater than $V_{d c r e f}$, the converter stops delivering power from the battery/dc side. Here a proportional controller detects the error signal of the dc-link voltage.

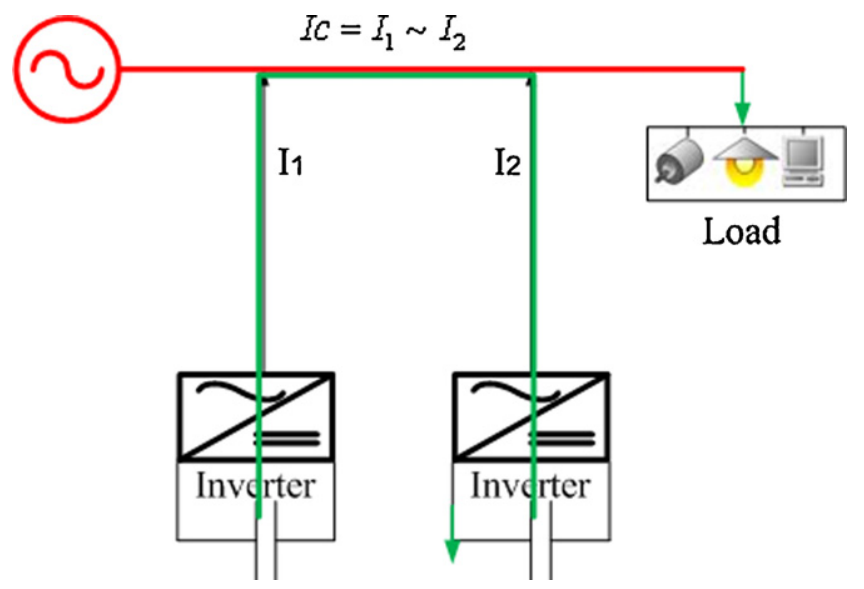

Fig. 2. Circulating current flow between the parallel inverters. 
(a)

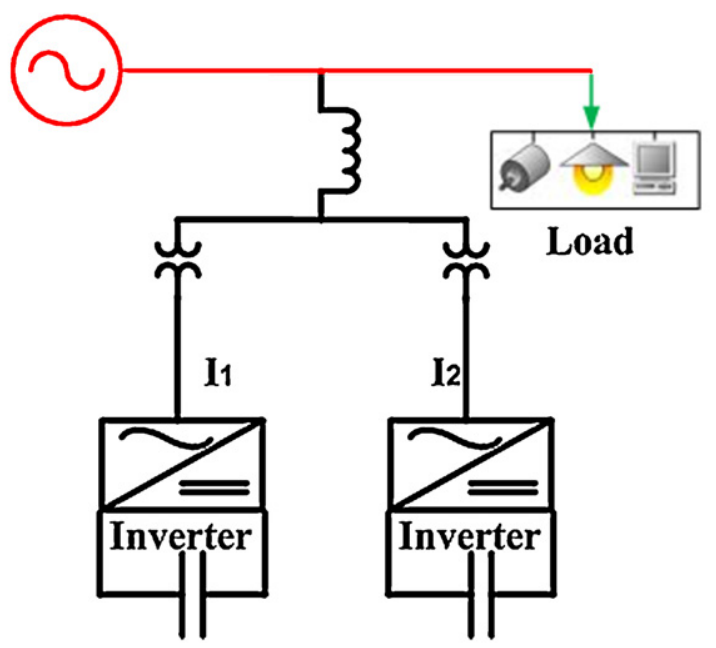

(b)

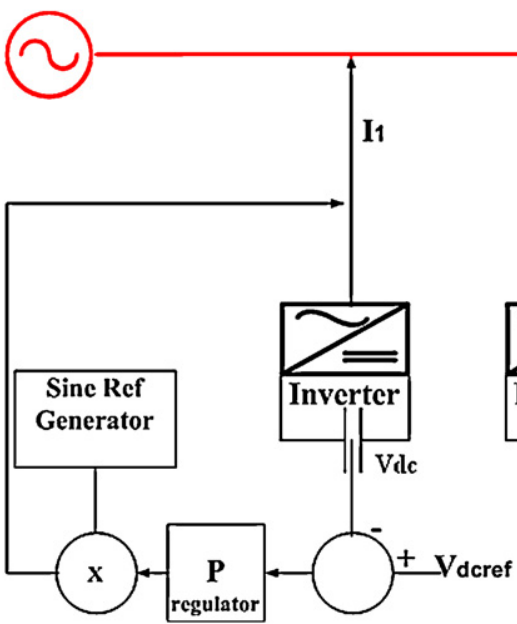

Fig. 3. (a) passive control using isolation transformer; (b) Regenerative control structure to avoid dc-link overvoltage/to prevent circulating current.

\section{Control strategies in parallel operation of inverters}

In distributed generation (DG) systems, either connected to or off the grid, there may be more than one inverter acting in parallel. Therefore, distributed uninterruptible power supply (UPS) systems as well as the parallel operation of voltage source inverters with other inverters or with the grid, are sensitive to disturbances from the load or other sources and can easily be damaged by overcurrent. Hence, careful attention should be given to system design and the control of parallel operation of inverters. Several control methods are proposed and discussed in [3,10-22]. When two or more inverters operate in parallel, the following features must be achieved: (1) amplitude, frequency and phase synchronization among the output voltages of inverters, (2) proper current distribution according to the capacities, (3) flexibility and (4) hot-swap feature at any time [14].

Some of the outcomes of recent research on parallel operation of inverters are given below. The conventional control strategies for the parallel-connected inverters can be classified into two types; active load sharing/current distribution and droop control.

\subsection{Active load sharing/current distribution}

The objective of the active current distribution control is to generate a reference current for each parallel-connected inverter and this can be subdivided into;

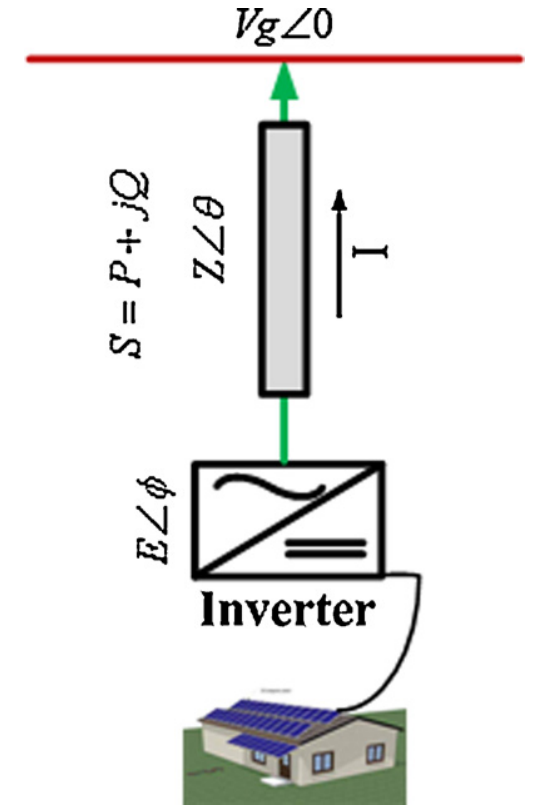

Fig. 4. Inverter connected to the grid.

(i) central limit control (CLC);

(ii) master-slave control (MSC);

(iii) average current sharing (ACS)/distributed logical control (DLC);

(iv) circular chain control (3C).

In CLC mode, all the modules should have the same configuration and each module tracks the average current to achieve an equal current distribution [14]. Perfect and equal current distribution can be achieved by using DSP-based control for the voltage and current controller and by tracking the averaged inductor current of the inverters. Thus the system stability and robustness can be improved [15].

In the MSC method, one inverter is specified as the master, and all others are as the slaves. The master inverter supplies a reference current to the slave inverters. Thus the master module is responsible for the output voltage regulation [16]. In such a system, if the master module fails, the system will shut down. This is a major drawback. This can be partially overcome by introducing a separate current-controlled PWM inverter unit to generate the distributing current independent for the slave inverters. Hence, precise current division between the inverters are very important. This strategy is easy to implement in the parallel operation of UPS [11]. In other cases, another module can take the role of master in the event of a main master unit failure. The control scheme can be of dedicated, rotary or high-crest current type [17].

In the MSC and CLC methods, the output currents of all parallel-connected inverters must be collected, and the number of parallel-connected inverters must be pre-known. If one of the parallel-connected inverters fails, the parallel-connected system will fail. This problem can be overcome by the DLC mode where redundancy is also achievable.

In the ACS/DLC mode, an individual control circuit is used for each inverter. The current control mode is used to control its output current and to trace the same average reference current. When a defect is found in any module, others can still operate in parallel [18-20]. It can also be used as a power-sharing technique where each inverter controls the active and reactive power flow in order to match the average active power of the system [21].

In the $3 \mathrm{C}$ mode, the successive module tracks the current of the previous module to achieve an equal current distribution, and the 

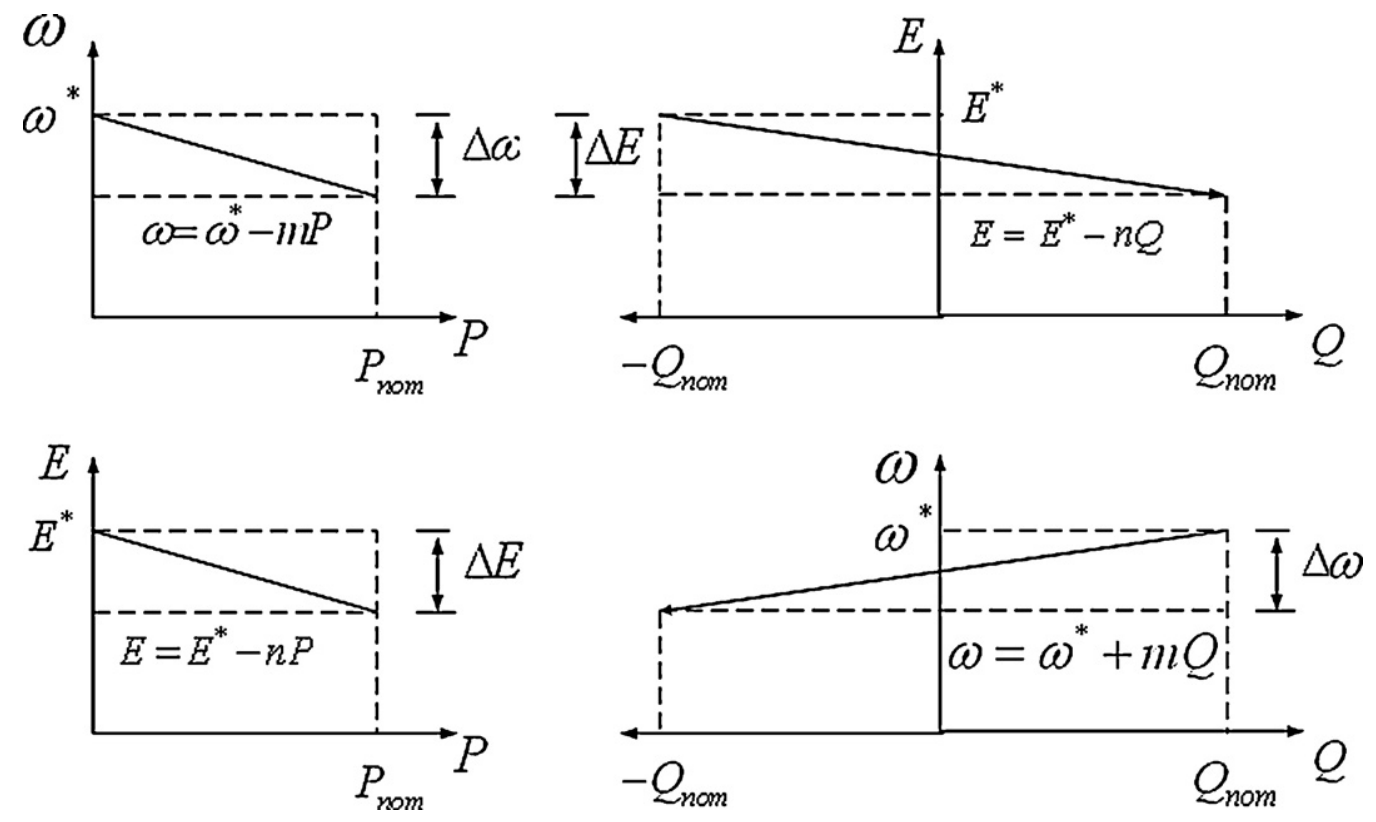

Fig. 5. Static droop characteristics $P-w$ and $Q-E$.

Table 1

Output impedance impact over power flow controllability [26].

\begin{tabular}{ll}
\hline Output impedance $(Z)$ & $Z=j X\left(\right.$ inductive: $\left.\theta=90^{\circ}\right)$ \\
Active power $(P)$ & $P=\frac{E V}{X} \sin \phi \cong \frac{E V}{X} \phi$ \\
Reactive power $(Q)$ & $Q=\frac{E V \cos \phi-V^{2}}{X} \cong \frac{V}{X}(E-V)$ \\
Frequency droop $(\omega)$ & $\omega=\omega^{*}-m P$ \\
Amplitude droop $(E)$ & $E=E^{*}-n Q$ \\
$m$ & $\Delta \omega / P_{\text {nom }}$ \\
$n$ & $\Delta E / 2 Q_{\text {nom }}$
\end{tabular}

$$
\begin{aligned}
& Z=R \text { (resistive: } \theta=0^{\circ} \\
& P=\frac{E V \cos \phi-V^{2}}{R} \cong \frac{V}{R}(E-V) \\
& Q=\frac{E V}{R} \sin \phi \cong-\frac{E V}{R} \phi \\
& \omega=\omega^{*}+m Q \\
& E=E^{*}-n P \\
& \Delta \omega / 2 Q_{\text {nom }} \\
& \Delta E / P_{\text {nom }}
\end{aligned}
$$

first module tracks the last one to form a circular chain connection. The output voltage and current of each inverter can also be varied and internally controlled to achieve a fast dynamic response [13]. A coordinated control strategy for different load sharing controls can be implemented to eliminate the circulating currents due to unbalance of parallel inverters [22].

\subsection{Droop control}

The droop control method for the parallel-connected inverters can avoid the communication mismatch of reference current. It is also defined as wireless control (WC) with no interconnection between the inverters. In this case, the inverters are controlled in such a way that the amplitude and frequency of the reference voltage signal will follow a droop as the load current increases and these droops are used to allow independent inverters to share the load in proportion to their capacities [23].
This technique is then improved for non-linear load where harmonic components can be shared properly [24]. The impact of line impedance on reactive power sharing in the conventional frequency/voltage droop concept is further enhanced in [25] to make the controller ideally suited for distributed ac power supply systems.

\subsection{Outcomes}

A detailed review and performance comparison of these control strategies has been presented in [26] which shows that within active load sharing control schemes, current-sharing control is good for output voltage regulation and harmonic current control. However it requires high speed communications. Active power sharing requires low bandwidth communication for active and reactive power sharing, but the harmonic power sharing is poor and therefore sharing non-linear loads with a high crest factor is a

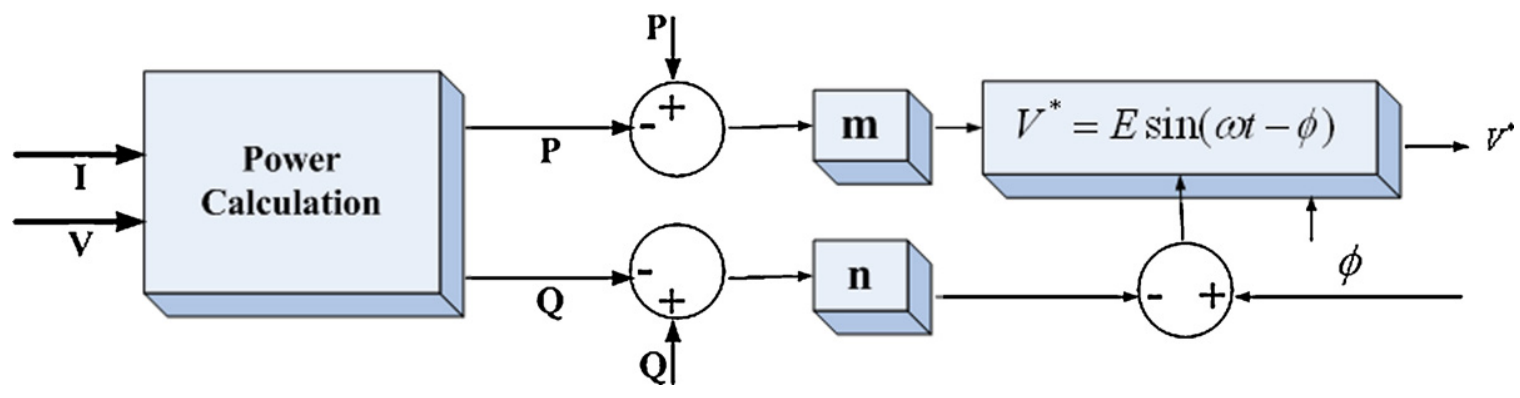

Fig. 6. A simple block diagram of $P / Q$ droop controller. 


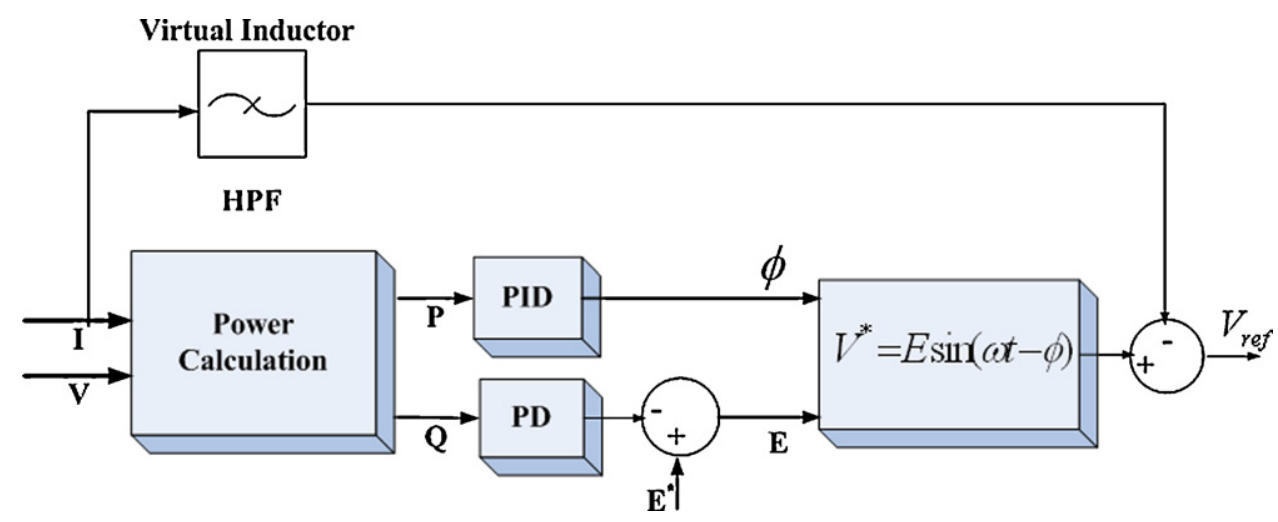

Fig. 7. PD and PID based conventional droop control to improve the transient performance.

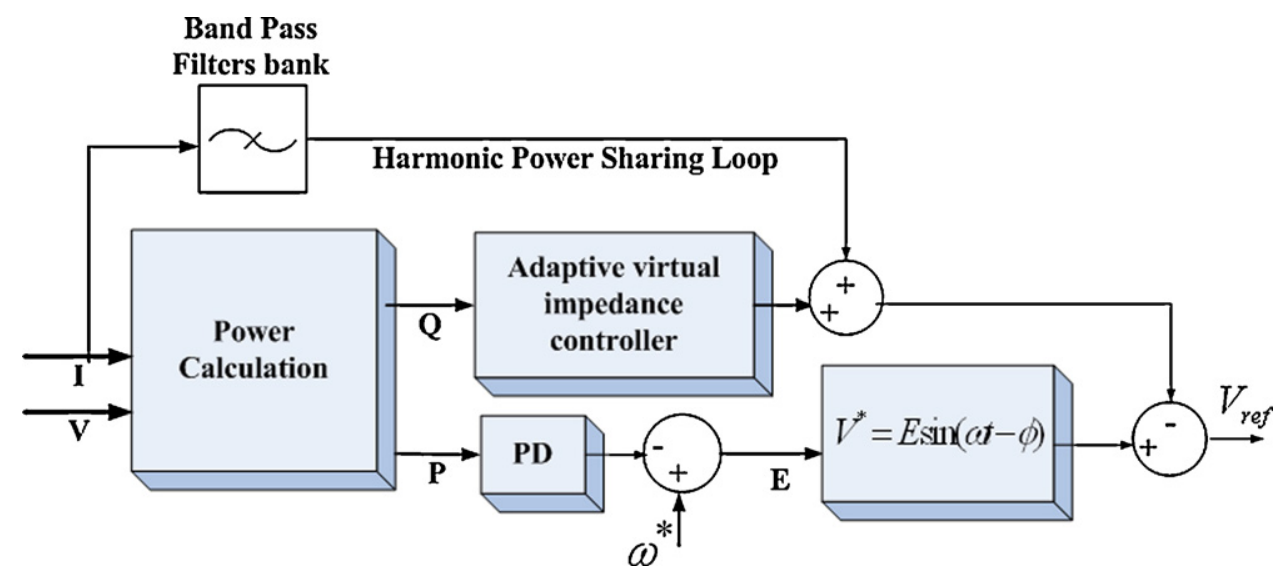

Fig. 8. Adaptive Virtual Impedance controller in droop control scheme.

problem. Active synchronization is also a major problem for both the schemes.

Within the active load sharing scheme, the centralized and the master-slave controller need a main inverter module to be set as the central control unit and this would lower the system reliability. Modularity and redundancy are very low for both of the controllers. The average current sharing/distributed logic controller, for which there is no central controller and thus has higher modularity, requires a current sharing control loop to manage the transient and stability problems. The circular current control strate-

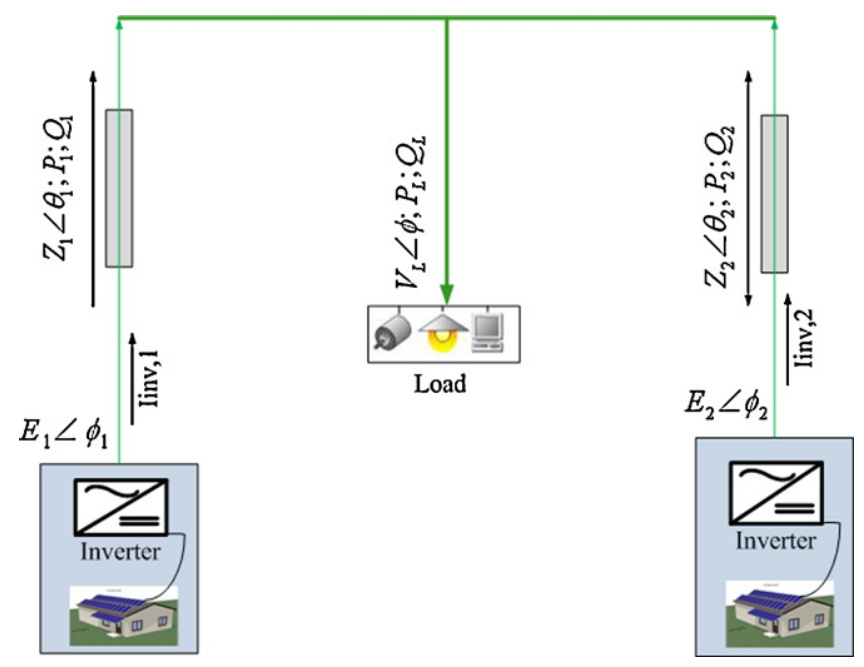

Fig. 9. Power sharing through droop control method. gies require more communication between each of the inverters as well as a circular path for current distribution. This is suitable when forming an ac power ring.

In general, while the active current distribution control method is perfect for well balanced current distribution, the intercommunication process of the generated reference current of parallel-connected inverters can be subject to interference, and thus the system reliability will be degraded. In addition, the communication of the reference current among the parallel-connected inverters is difficult in some applications such as a distributed generation system.

On the other hand, droop control or the wireless control with no interconnection of lines could be more useful for either active load sharing or for a distributed generation network connected to the grid or off-grid. Some improvement in control has also been achieved to overcome its limitations such as poor transient response. Hot-swap operation is another benefit of using the droop control method. Low sensitivity to line impedance unbalances and harmonic power sharing capability are the other advantages of a droop controller.

\section{Working principle of droop control method}

The idea of the droop control method in the parallel operation of an inverter or APF is to control the system without interconnection between each other. Inverters can be placed in different locations within the microgrid or the DG system. In that case, the droop control method is very effective for inverters where active and reactive power flow predominantly depends on power angle/frequency and the output voltage amplitude of the inverters. Here, inverters are generally operated in the voltage-mode control and the phase and 
(a)

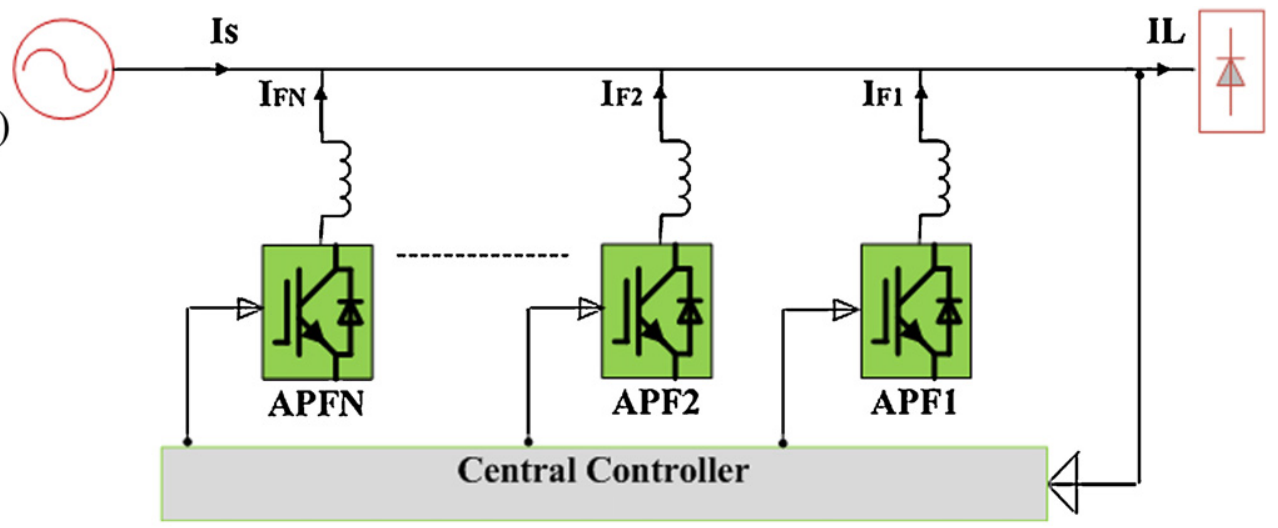

(b)

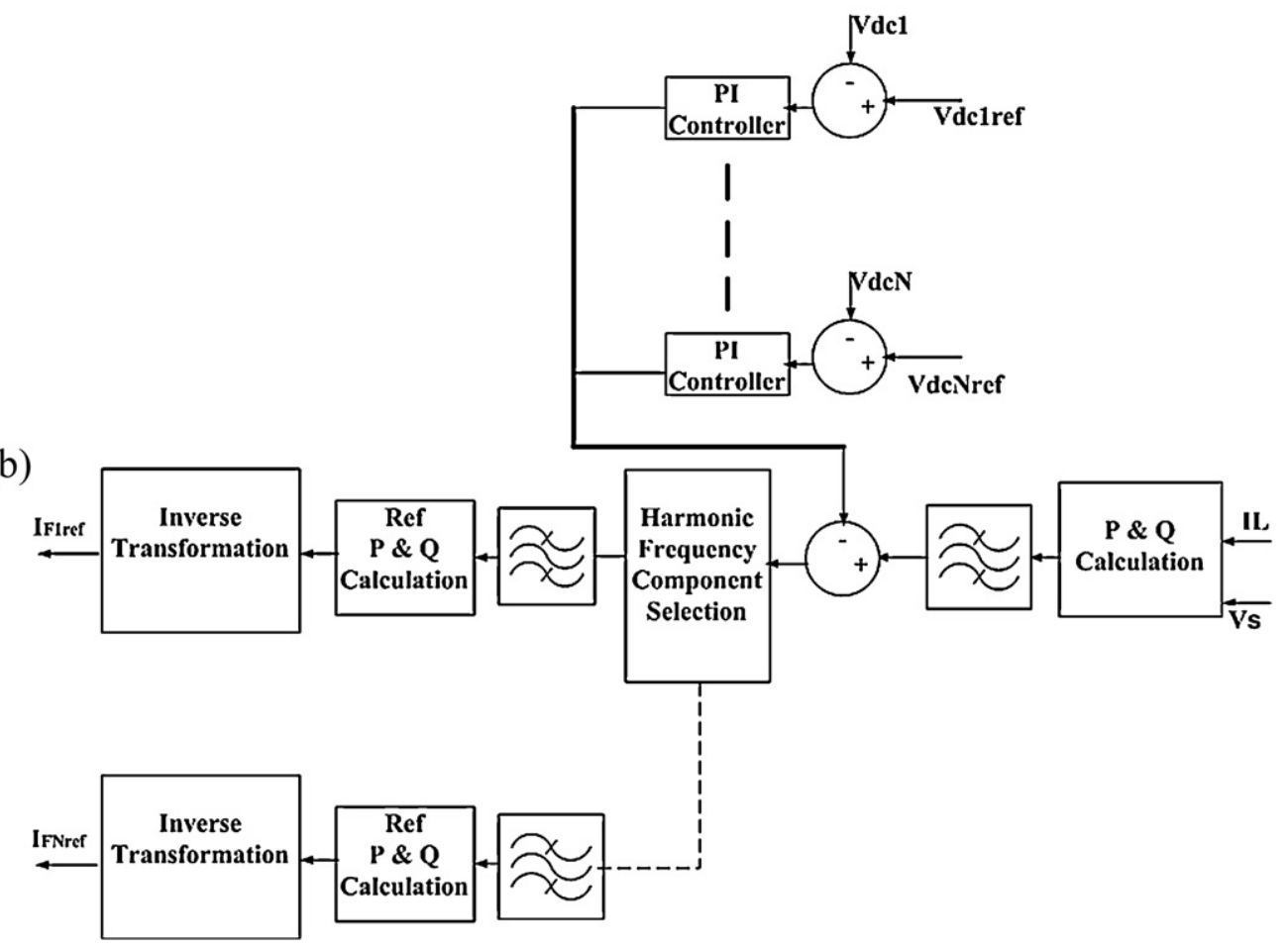

Fig. 10. (a) Centre Mode Control Technique; (b) Reference Current Generation technique for Frequency Splitting Control.

amplitude of the output voltage of the inverters are the control parameters. The controller is defined in such a way that the amplitude and frequency of the reference voltage signal follow a droop as the load current increases.

An inverter connected to the common bus through a decoupling impedance is shown in Fig. 4. Usually the inverter output impedance is highly inductive, and hence the active and reactive powers drawn to the bus can be expressed from Eqs. (1) and (2) as [1];

$P=\frac{E V}{X} \sin \phi$

$Q=\frac{E V \cos \phi-V^{2}}{X}$

where $X$ is the output reactance of an inverter, $\phi$ is the phase angle between the output voltage of the inverter and the voltage of the common bus, $E$ and $V$ are the amplitude of the output voltage of the inverter and the grid/load voltage, respectively. From the above equations, it is found that the active power is predominately dependent on the power angle $\phi$, while the reactive power mostly depends on the output-voltage amplitude $E$. Consequently, parallel operation of inverters in wireless-control mode uses the conventional droop method, which introduces the following droops in the amplitude $E$ and the angular frequency $\omega$ of the inverter output voltage [23];

$\omega=\omega^{*}-m\left(P_{0 i}-P_{i}\right)$

$E=E^{*}-n\left(Q_{0 i}-Q_{i}\right)$

$\omega^{*}$ and $E^{*}$ are the output voltage angular frequency and amplitude at no load, and $m$ and $n$ are the droop coefficients for the frequency and amplitude, respectively. $P_{0 i}, P_{i}$ and $Q_{0 i}, Q_{i}$ represent the power rating and actual power output for active and reactive power, respectively. If droop coefficients are increased, then good power sharing is achieved at the expense of degrading the voltage regulation, which can be acceptable if the frequency and amplitude deviations ( $\Delta \omega$ and $\Delta E$ ), as shown in Fig. 5 , are typically $2 \%$ and $5 \%$, respectively [27].

The droop control law is determined by the output impedance angle $\theta$, as shown in Table 1. Fig. 5 also shows the droop control functions depending on the output impedance. Here $m$ and $n$, the 


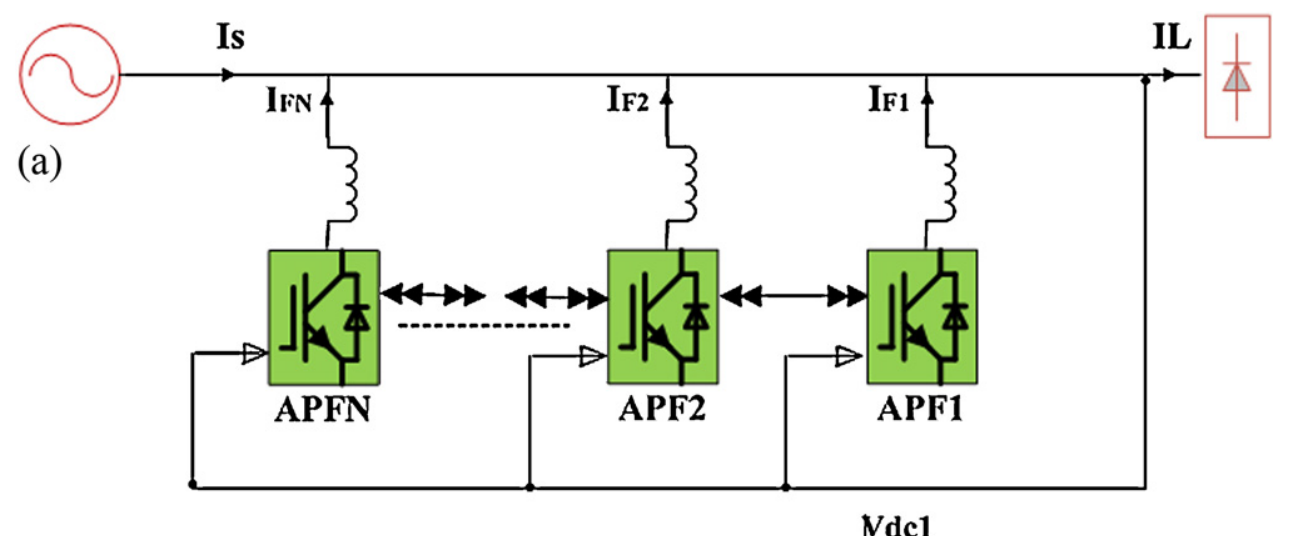

(b)

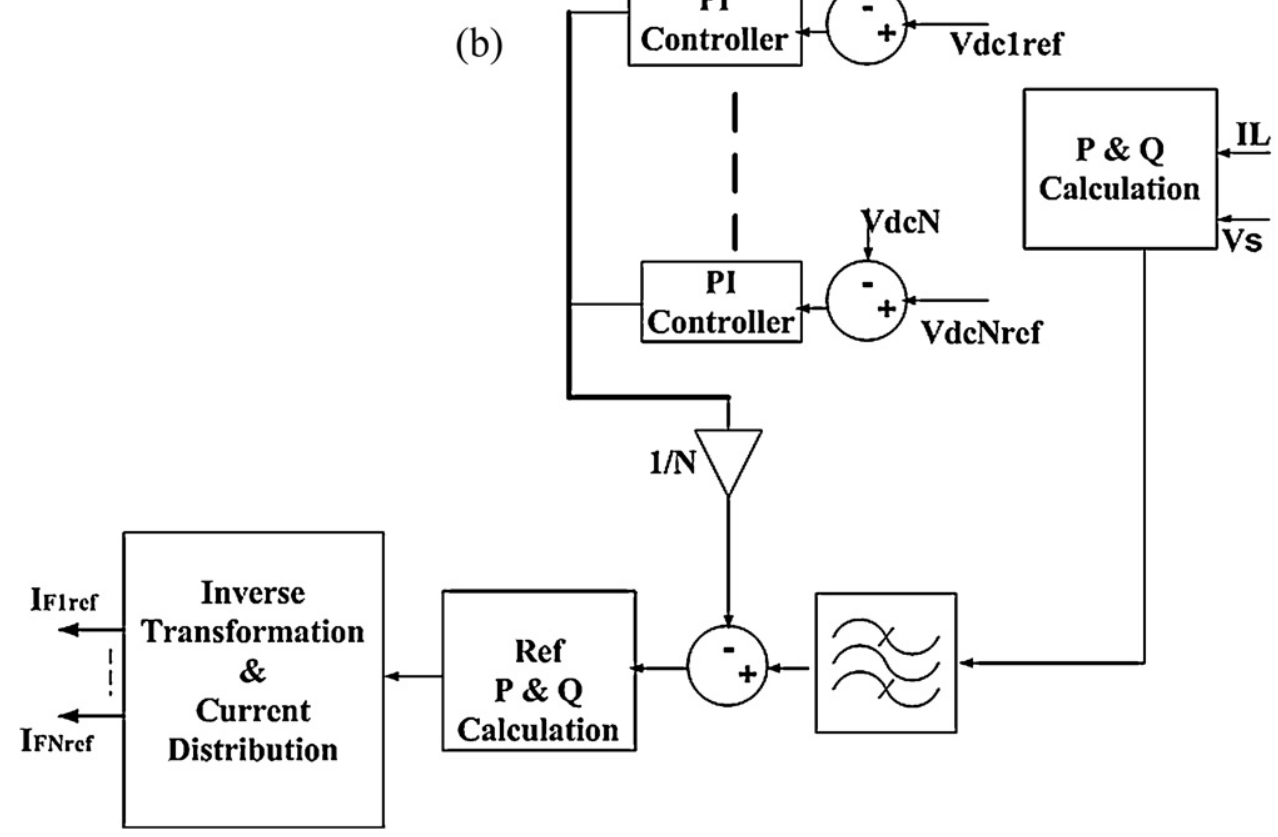

Fig. 11. (a) Distribute Control Technique; (b) Reference Current Generation technique for Power Splitting Control.

controller gains, are chosen as functions of the nominal values of $P$ and $Q$, respectively. Fig. 6 shows a simple block diagram of a droop controller.

\section{Parallel operation of inverters in DG or microgrid}

Recent work on parallel operation of inverters in DG has concentrated on two applications: a) standalone AC system-Microgrid (island/off-grid mode) and b) grid-interconnection to the utility. In island mode of operation, a number of DGs supplies all the power needed by the load, like the parallel operation of the uninterruptible power supply (UPS) systems. In a grid-tie operation, each distributed energy source is connected in parallel to the utility, and directly provides power to the grid in order to cover increased power required by the loads.

Considering the parallel operation of DGs in any of the modes, voltage stability is a major concern. If appropriate controlling is not done, then the power system may become unstable under the heavy load condition and thus exhibiting voltage drops that can lead to a voltage collapse and resulting in a black-out. Again, when renewable energy sources are connected to the grid, the system should have the ability to dispatch the optimum energy as well as to control the power conversion system in (i) utility interactive grid- tie inverter mode, (ii) off-grid inverter back-up mode, (iii) active rectifier mode and (iv) active power filter mode.

As the parallel operation of inverters for load sharing conditions and the application of DG in microgrids are increasing rapidly, control strategies of parallel inverters in microgrids are being given more attention. A countable number of researches have been done considering active load sharing condition [14-22] and droop control [23-29] or a combination of both [30-32]. Due to the advancement of digital signal processing techniques, some of these controlling methods have been applied to achieve voltage harmonics elimination and fast recovery performance on load transient in digital mode [31-35]. Transient response can also be improved by introducing proportional-integral-derivative (PID) terms [27], as shown in Fig. 7, or an adaptive output impedance controller [28], as shown in Fig. 8, into a conventional droop scheme. In addition, an instantaneous current control loop is also included to ensure correct sharing of harmonic components when supplying nonlinear loads.

The possible resonance due to long wiring cables having nonnegligible inductance and resistance and its detrimental effect on system stability and performances should be considered during the design stage $[36,37]$. The line impedance ratio between the grid and inverter can be implemented to cancel voltage harmonic disturbances [27]. A grid impedance parameter estimation technique in 

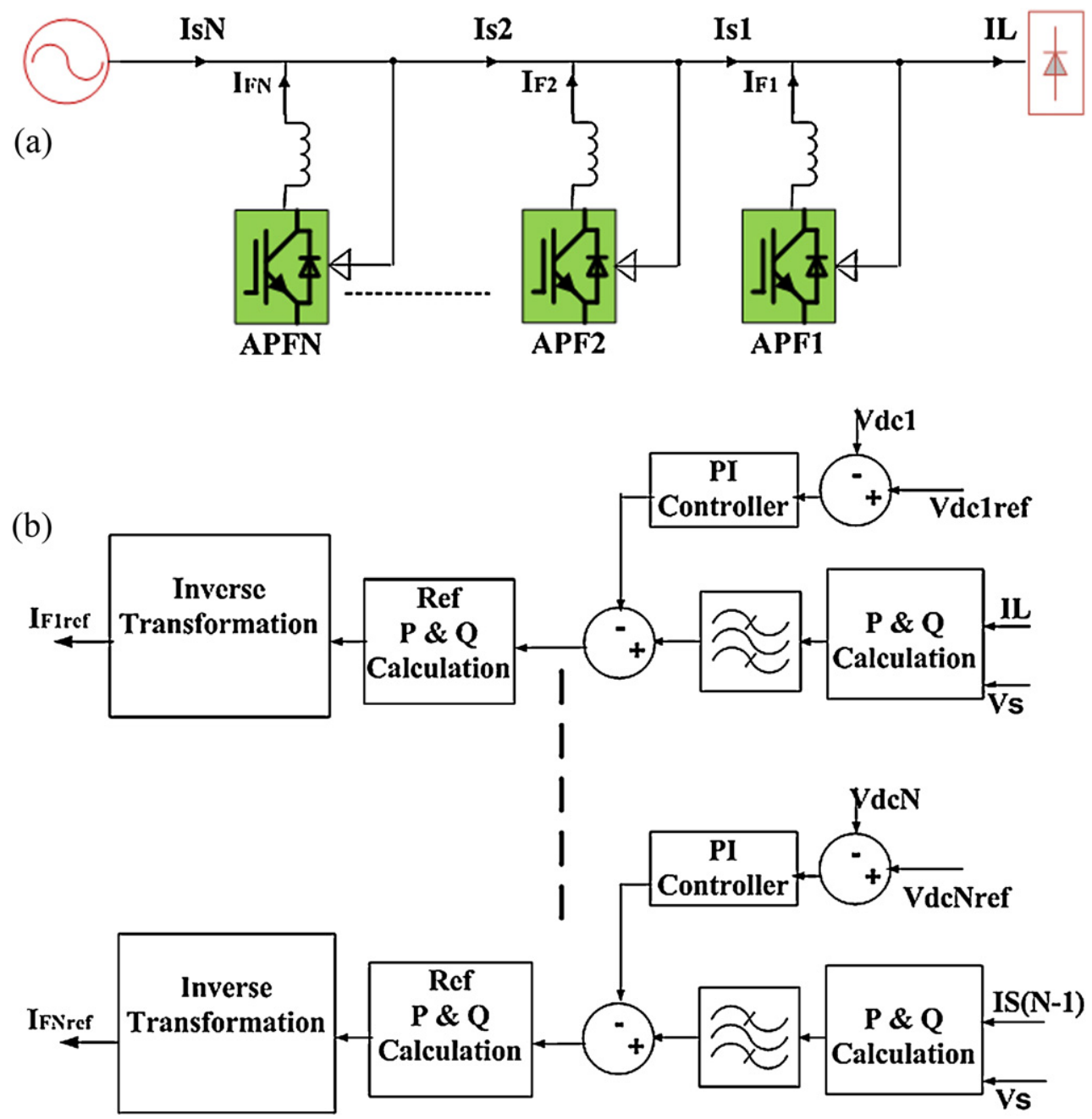

Fig. 12. (a) Capacity Limitation Control Technique; (b) Reference Current Generation technique for Capacity limitation control.

advance has been presented in [38] and then applied to an adaptive droop controller to operate inverters in grid-connected or islanded mode.

Fig. 9 shows that the droop control method can also be applied where DGs are working in parallel to cover the local load demand and sharing the common load during off-grid conditions [39]. Further improvement of stability and load sharing capability in an autonomous microgrid has been achieved by implementing a supplementary controller into the droop control method [40].

Most of the power electronics converters are based on the variable frequency controller. Research on fixed or constant switching frequency controllers by using simple circuitry has also been conducted. One-cycle control (OCC) is one of these types which can be successfully implemented in a grid connected inverter with its parallel operation mode [41]. Again, as the switching frequency of the inverter is fixed, a conventional load-frequency control scheme cannot be used for load-sharing control. To alleviate this problem, a load-voltage control scheme has been developed in [42] where the control strategy distributes the load among the different energy sources based on their pre-defined load-voltage droop characteristics.

\section{Control strategies in parallel operation of APF}

Like inverters and UPS, the custom power devices (CPD) are finding greater applications as interfacing and compensating devices in distributed generation systems for power quality improvement as well as storing energy to work as a back-up UPS system during islanded mode of operation. The magnitude of compensating harmonic currents and required filter bandwidth determines the power rating and switching frequency of active power filter (APF). In high power applications, the whole spectrum of harmonics may not be filtered out by a single converter due to the limitations on switching frequency and power rating of the semiconductor devices. Therefore, to handle a larger portion of load power, increasing its capacity is essential. One of the conventional solutions of this typical design problem of APFs is hybrid configuration, which reduces converter voltage and power rating by using multilevel inverter; but increases the cost due to an additional step-down transformer, and design complexity for series or parallel connection of switching devices. The approaches with multiple inverters have also been demonstrated to be very effective for increasing the capacity.

Design analysis with experimental validation of a multi-module parallelable three-phase active power filter (centre mode) has been proposed first in [43] to solve the problems of capacity enlargement and load unbalance compensation encountered by the shunt APF with a three-arm topology. The disadvantage of the proposed method was that the malfunction of any inverter will cause erroneous compensation due to the generation of a current command which is not independent of other inverters. Therefore, another proposal was made by the same author in [44] with a capacity 


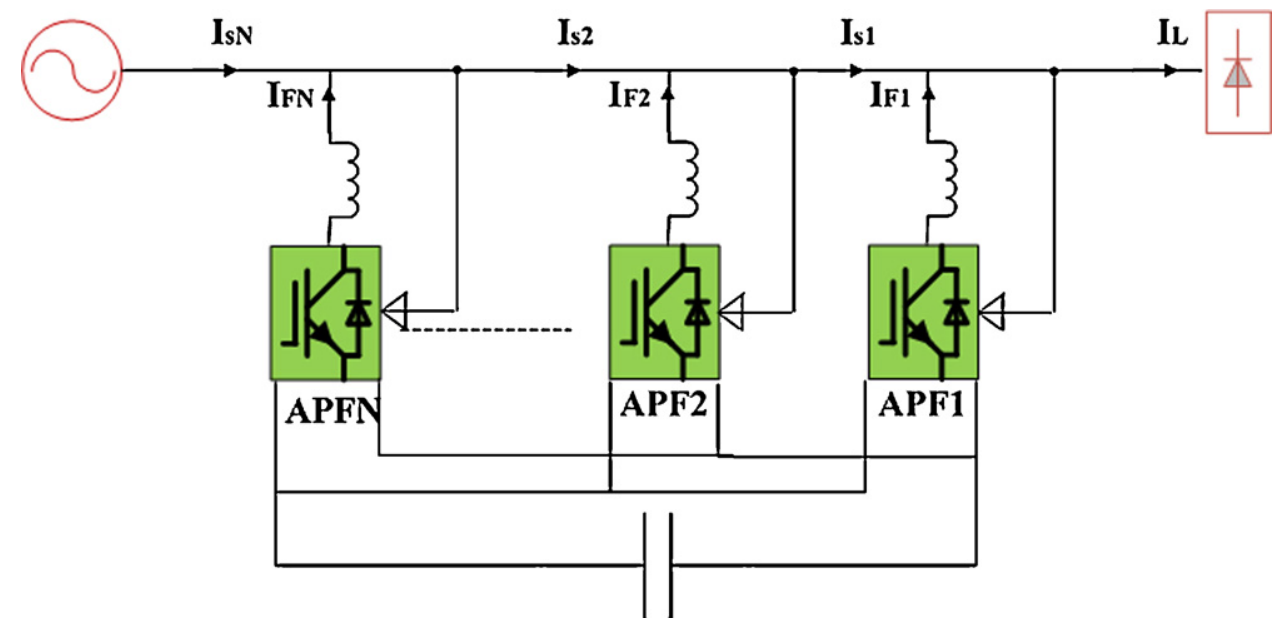

Fig. 13. Parallel inverters with common dc link capacitor.

limitation technique. In that case, APFs are connected in a cascade mode which shows the advantages of high flexibility, reliability due to no control interconnection and reduced power capacity demand of APFs. The disadvantage was that one APF treats other APFs on its load side as a part of its load. A third approach has been proposed in [45], which is based on power splitting. An overview of these techniques has been given below and present research outcomes along with the advantages and disadvantages of these techniques are also described.

\subsection{Frequency splitting (FS)/centre mode control (CMC)}

A central control unit is used to measure the total harmonic components and then each APF is assigned to compensate a specific harmonic component. Therefore it requires the minimum number of harmonic detection sensors, shown in Fig. 10(a). It can also be referred to as concentrated control. The technique for reference current generation has been presented in Fig. 10(b). If the sensing load current is $i_{L}$ then the harmonic current will be, $i_{L H}=i_{L}-i_{L 1}$ where $i_{L 1}$ is the fundamental component of the load current and $h$ is the number of harmonic components. In this mode, if there are two APFs working in parallel and one is responsible for reactive power compensation, then the other one will compensate the harmonics $[4,46]$.
The operational advantage is that the APF module which deals with the higher order harmonics should have the higher switching frequency. Since the harmonic current magnitude is inversely proportional to the harmonic order, the power rating is low. Thus it also helps to reduce the switching losses. The main disadvantage is that the APF modules are not identical and therefore replacement requires a similar one.

\subsection{Power splitting (PS)/distributed control (DC)}

In this case, compensating total harmonic current is equally distributed to the APFs and therefore identical modules are required. If there are $\mathrm{N}$ modules operate then the current reference of each module will be $I_{F N}=i_{L h} / N$. Since it maintains interconnection between the inverters, number of sensors are also higher than the central control mode, as shown in Fig. 11(a). The reference current generation technique has been depicted in Fig. 11(b). The main advantage is its easy maintenance and installation.

It is clear that in both central and distributed control system, the reference current of each APF are resulting from the same $P$ and $Q$ calculating algorithm block and therefore all the APFs maintain an interconnection control. Hence a fault in any communication or malfunctioning of any APF can cause the system to halt.

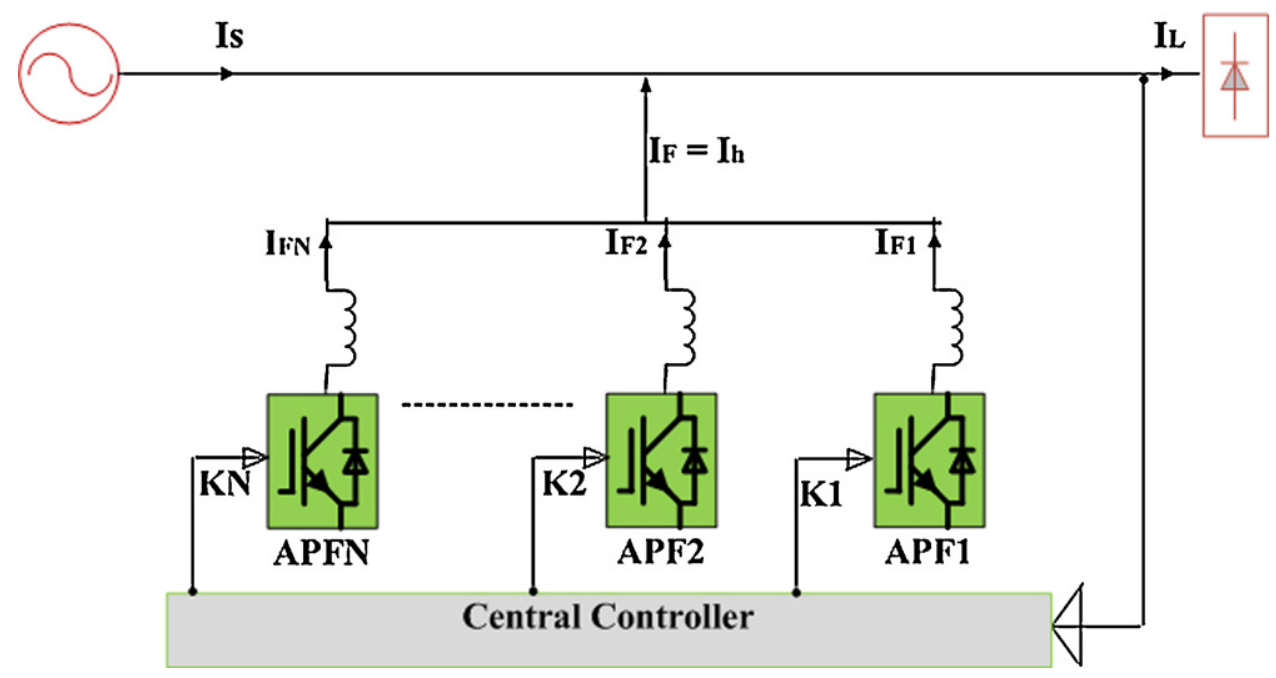

Fig. 14. Parallel operation of APF with a combination of central control and capacity limitation. 


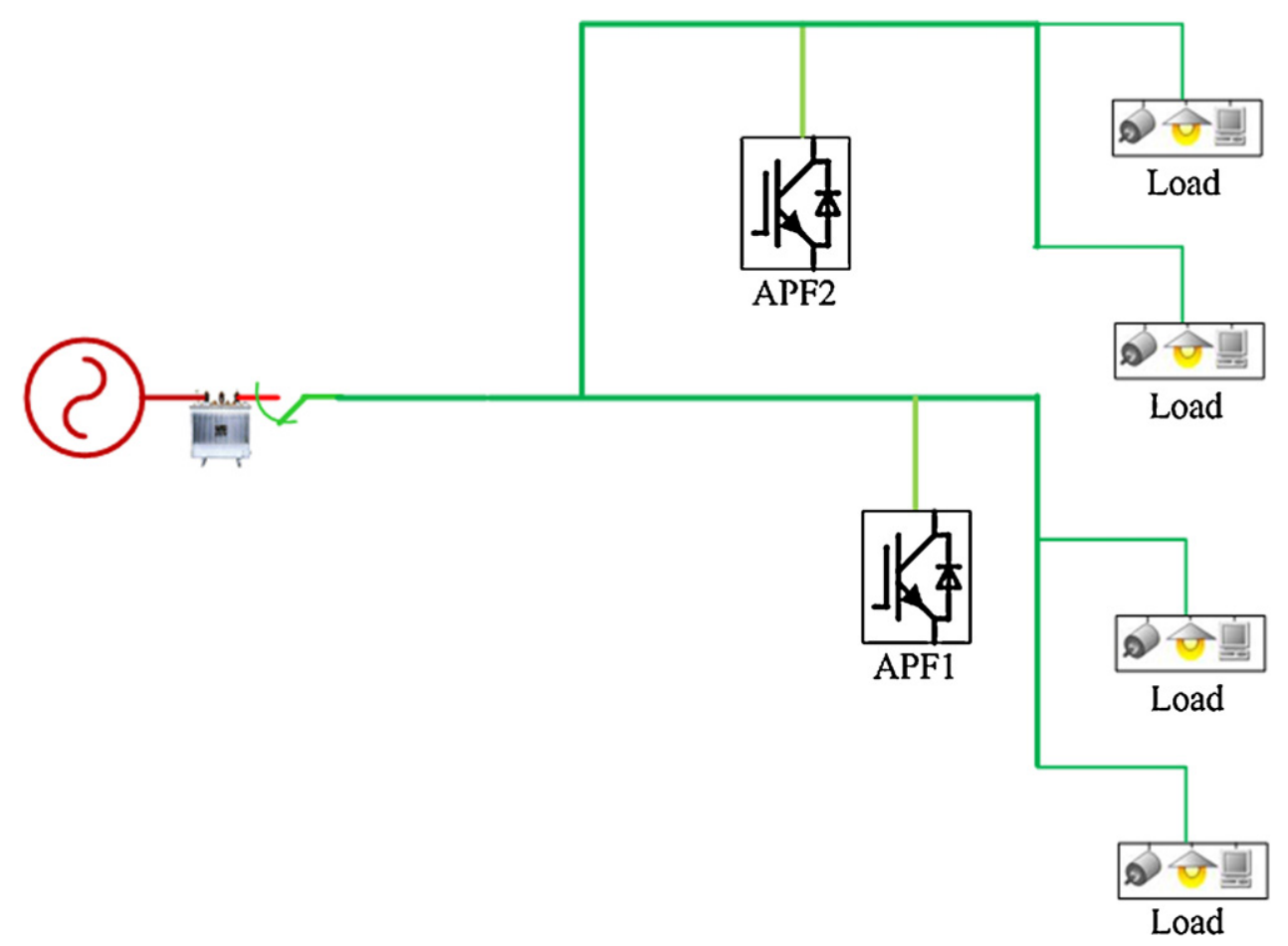

Fig. 15. Parallel operation of APFs with different feeder.

\subsection{Master-slave control (MSC)/capacity limitation control (CLC)}

In this mode, each APF compensates harmonic current according to its power rating. Each APF is independent and senses the current at the up/downstream of the node and therefore the maximum number of sensors is required, as shown in Fig. 12(a). Each APF only has to compensate the harmonic component left by the previous APF on its load side. Therefore generation of reference current for each APF requires separate $P$ and $Q$ calculation as shown in Fig. 12(b). The rating of each APF module is defined as;

$P=\frac{\sqrt{3}}{2} V_{d c} I_{F \max }$

In general, the APF near the load has higher capacity and the lowest bandwidth. As the APFs are not identical and work independently, power capacity enlargement is easier and the system reliability is also high. Also there is no central control and no information sharing between the APFs. Poor dynamic characteristics are the main disadvantages of this mode. But for steady-state conditions, CLC and PS show better performance than the FS [47]

A common dc link capacitor can be used for parallel inverters, shown in Fig. 13, to reduce the system cost [48], but it then raises the hardware design and control complexity due to the zero sequence current circulation between the inverters [49].

A new modular based APF controlled strategy with a combination of central control and master-slave mode has been proposed in [50] where each APF can operate independently and compensate the load harmonic current according to its own capacity-limitation. The output current of each APF is optimized in such a way that the APF with large capacity compensates more current and the one with small capacity compensates less current. In this way, the feasibility and security of modular APF has been guaranteed here. Fig. 14 shows the new control strategy where the total harmonic compensating current, $I_{F}=I_{F 1}+I_{F 2}+\ldots+I_{F N}$. Here,

$I_{F 1}=K_{1} I_{F} ; I_{F 2}=K_{2} I_{F} ; \ldots ; I_{F N}=K_{N} I_{F}$ and

$K_{N}=\frac{I_{r N}}{\sum_{j=1}^{N} I_{r j}} \frac{I_{r N}}{I_{F N r e f}}$

where, $I_{r}$ and $I_{F N r e f}$ represent the rated current and the compensating current reference of the selected APF.

These control strategies are applicable only for the active load sharing mode when multiple APFs are placed close to each other either at the point of common coupling or close to a large capacity load. When these APFs are working in different feeders or deal with separate loads, as in Fig. 15, then no central control mechanism is needed even though they are apparently in parallel operation [51].

Depending on the placement of the harmonic current sensor, there could be two types of harmonic compensation loops for duel shunt APF in parallel mode; either feedforward or feedback $[49,52,53]$. In general, feedforward topology is extensively used for its stability and ease of installation where the controlling method is based on a current-controlled source. On the other hand, feedback control is better for stationary conditions but become unstable during certain grid conditions. A combination of both controllers for two parallel APF rather than a single unit shows a better compensating result for both low and high order harmonics and also stable grid operation [53].

A comparative analysis with advantages and disadvantages of these techniques with topologies is presented in Table 2.

All the above approaches are for harmonic current compensation which is the primary function of parallel APF. This shunt APF can also be used as a compensator for voltage harmonics. Therefore, control of parallel APF for voltage harmonic compensation in a distribution line is another important issue. To detect the harmonic voltages, the active filter is characterized by behaving like a resistor for harmonic frequencies [54-56]. A cooperative controller based on voltage THD is proposed in [57] for parallel operation of multiple APF in a radial distribution feeder. A radial power distribution system with active power filter for voltage harmonic mitigation is shown in Fig. 16(a) whereas Fig. 16(b) shows a simple control method for the compensation. The real-time communications 
Table 2

Comparative analysis of parallel APFs controlling scheme with topologies.

\begin{tabular}{|c|c|c|c|}
\hline Harmonic compensation loop & CS & Advantages & Disadvantages \\
\hline 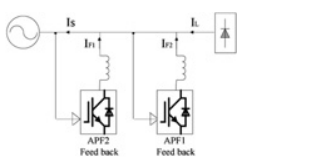 & MSC & $\begin{array}{l}\text { i. Compensate damping resonance (due to grid } \\
\text { and filtering capacitor at the load side) } \\
\text { ii. Better transient response in steady state } \\
\text { condition } \\
\text { iii. Reliable and redundant }\end{array}$ & $\begin{array}{l}\text { i. HDS - 4, thus increase the hardware } \\
\text { complexity } \\
\text { ii. Unstable for unknown grid condition }\end{array}$ \\
\hline $\begin{array}{c}\text { APF2 } \\
\text { Feed back }\end{array}$ & FS/PS & $\begin{array}{l}\text { i. HDS - 3, thus reduces the hardware design } \\
\text { complexity } \\
\text { ii. Reduce switching losses, if two inverters } \\
\text { operate at different frequency } \\
\text { iii. Good for load sharing between the filters }\end{array}$ & $\begin{array}{l}\text { i. Design for reference current selection is } \\
\text { critical; both inverters should be rated at same } \\
\text { nominal power } \\
\text { ii. Unstable for unknown grid condition } \\
\text { iii. Requires identical replacement }\end{array}$ \\
\hline$\stackrel{\mathrm{I}}{-} \mathrm{t}$ & MSC & $\begin{array}{l}\text { i. Does not depend on the voltage harmonic } \\
\text { distortion } \\
\text { ii. Good stability }\end{array}$ & $\begin{array}{l}\text { i. HDS - } 4 \text {, thus increase the hardware } \\
\text { complexity } \\
\text { ii. Load sharing between the filters is difficult }\end{array}$ \\
\hline Fed fonward Feed fonward & FS/PS & $\begin{array}{l}\text { i. HDS - 3, thus reduces the hardware design } \\
\text { complexity } \\
\text { ii. Easy maintenance and installation } \\
\text { iii. Good for load sharing between the filters }\end{array}$ & $\begin{array}{l}\text { i. Design for reference current selection is } \\
\text { critical; both inverters should be rated at same } \\
\text { nominal power }\end{array}$ \\
\hline $\begin{array}{l}\text { APF2 API } \\
\text { Feed back Feed forward }\end{array}$ & MSC & $\begin{array}{l}\text { i. Harmonic compensation is better than that of } \\
\text { the above four configuration }\end{array}$ & $\begin{array}{l}\text { i. HDS - 4, thus increase the hardware } \\
\text { complexity }\end{array}$ \\
\hline 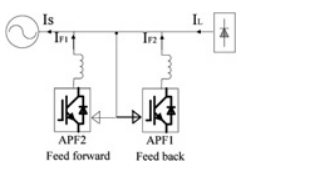 & FS/PS/MSC & $\begin{array}{l}\text { i. Harmonic compensation is better then all } \\
\text { other configurations } \\
\text { ii. HDS - 3, thus reduces the hardware design } \\
\text { complexity } \\
\text { iii. Reduce the line current ripple if the } \\
\text { inverters have the same switching frequency }\end{array}$ & $\begin{array}{l}\text { i. Redundancy is possible in load sharing mode } \\
\text { but may not be cost-effective } \\
\text { ii. Higher rated power for APF2 is required for } \\
\text { load sharing condition }\end{array}$ \\
\hline
\end{tabular}

CS - controlling Scheme; HDS - harmonic detection sensor.
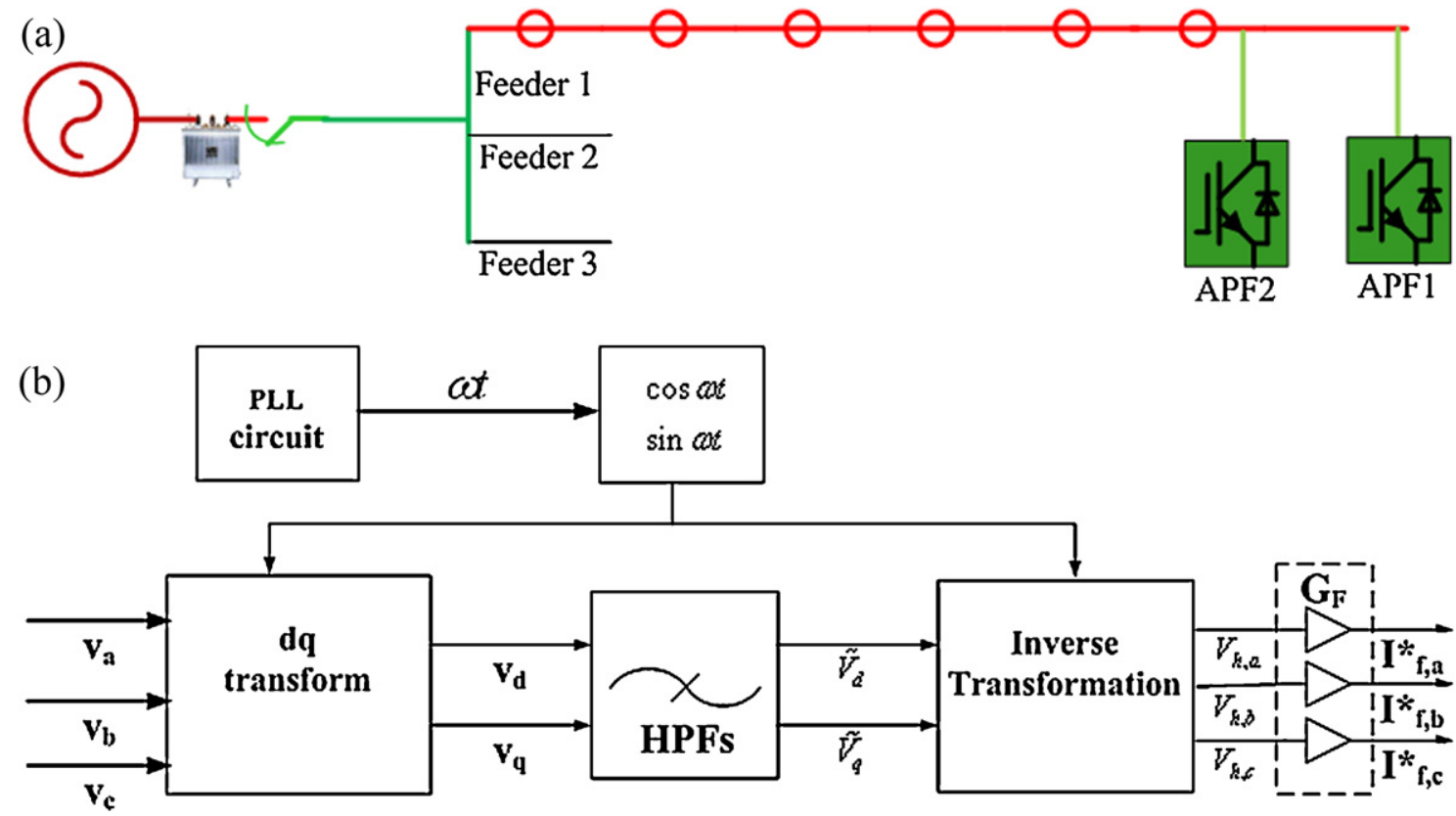

Fig. 16. (a) A radial power distribution system with active power filter; (b) a simple control circuit of the shunt APF as a voltage harmonic compensator. 


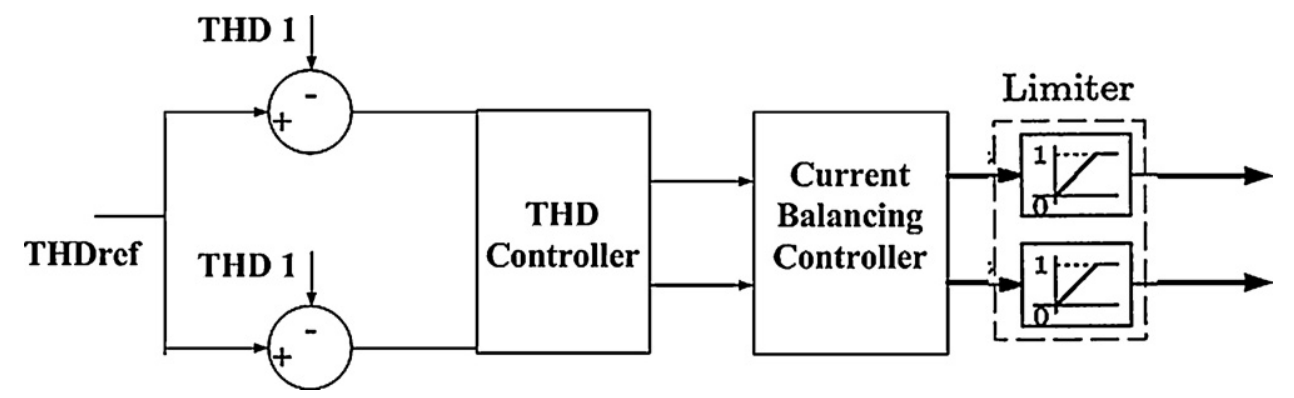

Fig. 17. Block diagram of cooperative control.

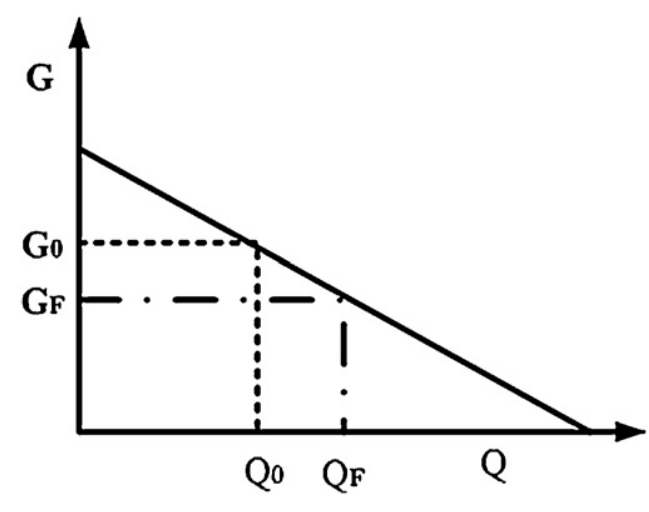

Fig. 18. Droop characteristics between $G-Q$.

among the APF units are required to coordinate the operations, which is overcome by introducing droop control method [58,59].

\subsection{THD based cooperative control}

The study in [55] shows that installation of an active or passive filter on a long-distance power distribution feeder may result in a "whack-a-mole effect" which is the magnification of voltage harmonics on the other buses where no filter is connected. This voltage harmonic distortion can be damped by introducing an active filter at the end of radial feeder [56,57]. The active filter detects voltage harmonics, $V_{h}$ at the point of installation, and then injects a compensating current, $I_{F}$ as follows:

$I_{F}=G_{F} \cdot V_{h}$

where $G_{F}$ is the control gain/conductance of the active filter.

An automatic gain adjustment was also proposed in [56] to damp out harmonic propagation without considering the circuit parameters of the distribution feeder. The purpose of cooperative control is to reduce the values of voltage THD over balancing the compensating currents. At first, the THD controller is set to be lower than a specified value to reduce the THD at the installation bus of one active filter. Then the current controller generates equal com- pensating currents for the APFs. Thus the cooperative controller makes a significant contribution to reduce the required current rating of each active filter. Fig. 17 shows a block diagram of cooperative control to reduce the voltage THD.

\subsection{Droop control for APF}

As has already been mentioned, droop characteristics relate the output phase angle of inverter with active power and the output phase voltage with reactive power flow. The function of APF is to compensate harmonic load current. The APF can also be used to control voltage harmonics at the point of installation. Therefore, the droop control can be implemented for both purposes of APF. The basics of these controls are briefly described below.

\subsubsection{Voltage harmonics control}

Using a high pass filter (HPF), $V_{h}$ can be extracted from the supply voltage, shown in Fig. 16(b), and then $I_{\text {Fref }}$ is generated. Final voltage command, $V_{F}$ is calculated as [58], Eq. (11) and the PWM then generates the corresponding gating signals.

$V_{F}=\frac{L_{F}}{\Delta T}\left(I_{F r e f}-I_{F}\right)+V_{S}$

where $L_{F}$ is the interfacing inductor and $\Delta T$ is the sampling period of the controller. A droop relationship between the $G_{F}$ and the VA consumption, $Q_{F}$ of the APF can be derived as;

$G_{F}=G_{0}+n_{F}\left(Q_{F}-Q_{F 0}\right)$

where $G_{0}$ is the rated conductance, $n_{F}$ is the slope of the droop equation and $Q_{F 0}$ is the rated capacity of the APF. The value of $n_{F}$ is determined by the VA rating of the APF to ensure the sharing of filtering workload in proportion with the capacity of the each APF. The droop relation between the $G$ and $Q$ is also depicted in Fig. 18.

\subsubsection{Current harmonics control}

To work as a harmonic current compensator, the APF current should deal with the node voltage, $V_{L}$ or voltage at the point of

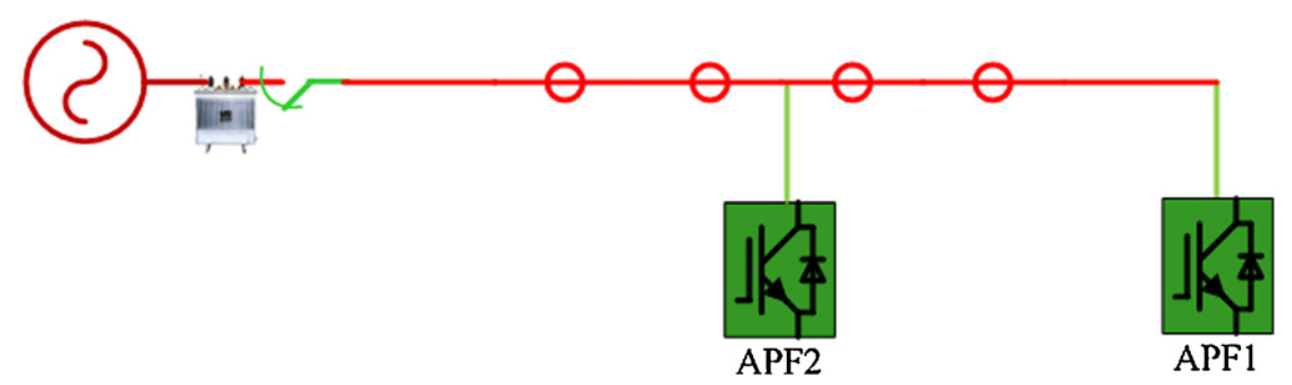

Fig. 19. Distributed APFs System. 


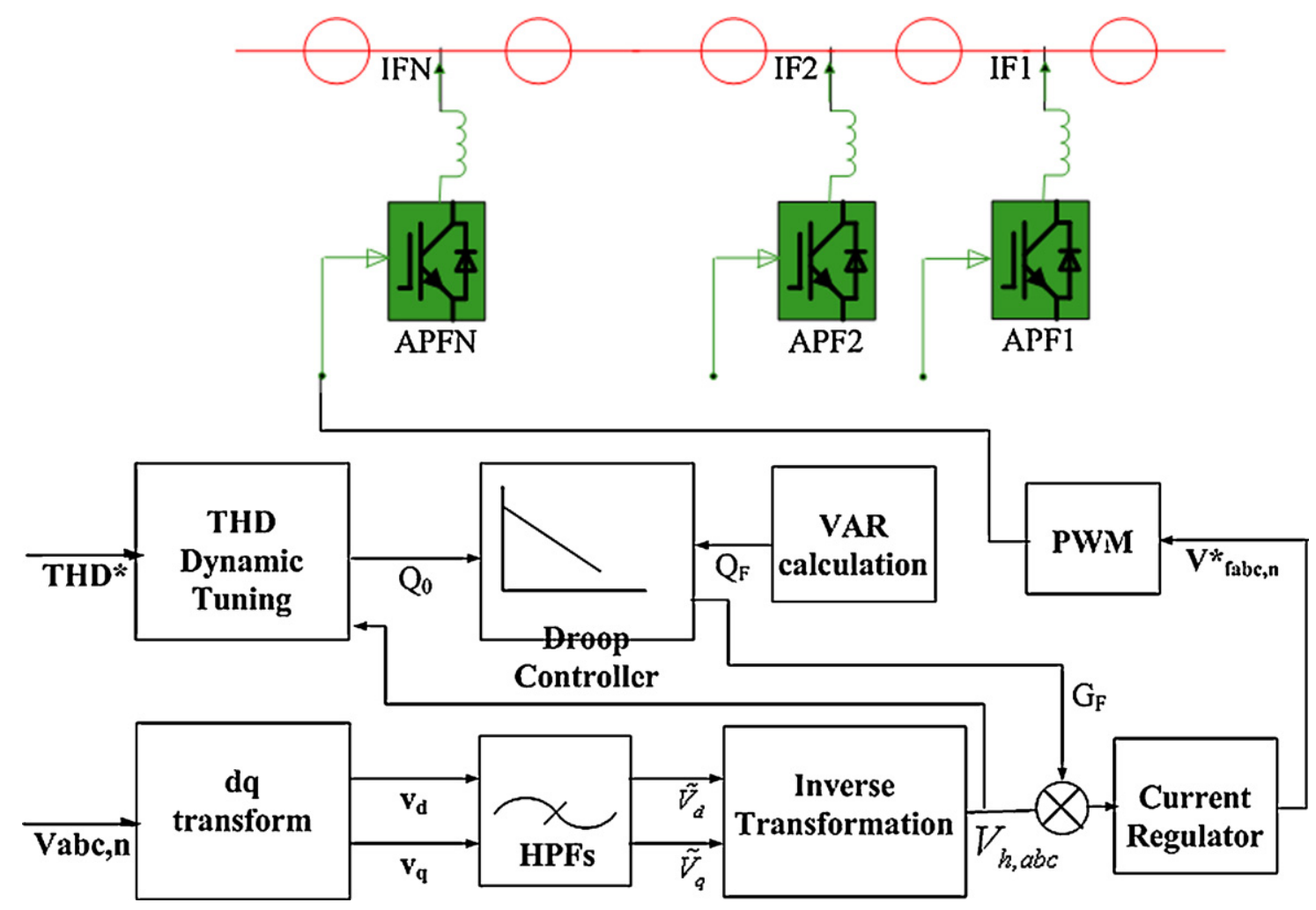

Fig. 20. A Dynamic tuning of THD for DAFS.

installation. In that case, the injected compensating current will be,

$I_{F}=G_{F} \cdot V_{L}$

The droop relation will be based on the conductance and nonfundamental power, $Q_{h F}$ of the APF and this can be derived as [60];

$G_{F}=G_{0}+n_{F}\left(Q_{h F}-Q_{h F 0}\right)$

where $Q_{h F 0}$ is the rated non-fundamental power of the APF. Nonfundamental power can be calculated as;

$Q_{h F}=\sqrt{Q_{F}^{2}-Q_{1 F}^{2}}$

$Q_{F}=V_{F} \cdot I_{F}$

$V_{F}$ is the output phase voltage of APF.

\subsubsection{Droop control for multiple parallel APF}

When multiple APFs with different ratings are used to compensate the reactive and harmonic components in a distributed environment, then the control should be based on locally available information. In that case, the droop controller can be effectively used for harmonic voltage and current compensation which is similar to the adjustment of fundamental voltage amplitude and frequency. Here, the droop coefficient values have to be adjusted according to the following relationships $[23,61]$;

$n_{1} \cdot Q_{10}=n_{2} \cdot Q_{20} \ldots=n_{i} \cdot Q_{i 0}$

The relation between the VA of the APF and rated capacity can also be expressed as [58];

$\frac{Q_{1}}{Q_{10}} \approx \frac{Q_{i}}{Q_{i 0}}$

Using the droop characteristic to share the current of a certain harmonic frequency has also been presented in [61]. The main advantages of droop control for multiple parallel APFs is that it can be used either when the APFs are in close proximity at the point of installation $[56,57,60]$ or in distributed mode with no interconnection between each others [58].

APFs in distributed mode can be termed as distributed active filter system (DAFS). Fig. 19 shows the DAFS where multiples APFs are installed at different locations of the distribution line.

The filtering capacity of the APFs is further improved by introducing a dynamic tuning method in the DAFS [58], as shown in Fig. 20, where the voltage THD at the installation point of each APF is used to adjust dynamically the VA capacity and the slope of droop characteristic. Here, the APFs adjust their filtering capability in response to increasing or decreasing of nonlinear loads in the system to maintain the voltage distortion at the allowable level. A discrete frequency tuning active filter is also proposed in [59] to suppress power system harmonics effectively. Here, the APFs operate as a variable conductance for each individual harmonic frequency. Each harmonic conductance is then dynamically adjusted according to the corresponding harmonic voltage distortion of the APF.

\section{Conclusion}

In this paper, the control strategies of parallel operation of DG inverters are initially described. Techniques for harmonic voltage and current compensation using APFs in parallel mode are also reviewed. From the inverter control strategies it is found that active load sharing control techniques have some limitations. Due to intercommunication requirement between the inverters, control complexity is significant. Although active load sharing techniques for parallel operation of a fixed number of inverters can be better due to its robust control, expansion of capacity due to the additional load may not be easy. On the other hand, droop control seems better for most purposes. Research indicates that most efforts are being put into droop control techniques due to its capacity expansion flexibility, independent inverters and hot-swap facilities. 
In the case of APFs in parallel operation, active harmonic load sharing techniques become more complicated due to the placement of harmonic current sensors or compensation topology. A comparative summary table has been prepared and it is found that a combination of feed-forward and feedback topology gives better results [53]. For multiple APFs, these controller designs will be more difficult. Therefore, research efforts have concentrated more on the droop control method. Implementing the basic ideas of droop control for parallel inverter operation, placement and controlling of APF has been advanced to distributed active filter systems which is very much suitable for distributed generation integration on a network or off-grid operation.

\section{References}

[1] Bergen AR. Power systems analysis. Englewood Cliffs, NJ: Prentice-Hall; 1986.

[2] Emadi A, Nasiri A, Bekiarov SB. Uninterruptible power supplies and active filters. 1st ed. LLC: CRC press; 2005.

[3] Kawabata T, Higashino S. Parallel operation of voltage source inverters. IEEE Trans Ind Appl 1988;24(2):281-7.

[4] Basu M, Das SP, Dubey GK. Parallel converter scheme for high-power active power filters. IEE Proc Electr Power Appl 2004;151(4):460-6.

[5] Rech C, Pinheiro JR. Line current harmonics reduction in multipulse connection of asymmetrically loaded rectifiers. IEEE Trans Ind Electron 2005;52(3):640-52.

[6] Ye Z, Boroyevich D, Choi JY, Lee FC. Control of circulating current in parallel three-phase boost rectifiers. IEEE APEC 2000:506-12.

[7] Pan CT, Liao YH. Modeling and coordinate control of circulating currents in parallel three-phase boost rectifiers. IEEE Trans Ind Electron 2007;54(2):825-38.

[8] Baumann M, Kolar JW. Parallel connection of two three-phase three-switch buck-type unity-power-factor rectifier systems with DC-link current balancing. IEEE Trans Ind Electron 2007;4(6):3042-53.

[9] Glauser HP, Keller M, Plüs A, Schwab M, Scherwey R. New inverter module with digital control for parallel operation. IEEE TELES Conf 2000:265-9.

[10] Holtz J, Werner KH. Multi-inverter UPS system with redundant load sharing control. IEEE Trans Ind Electron 1990;37(6):506-13.

[11] Jiann-Fuh C, Ching-Lung C. Combination voltage-controlled and currentcontrolled PWM inverters for UPS parallel operation. IEEE Trans Power Electron 1995;0(5):547-58.

[12] Hanaoka H, Nagai M. Development of a novel parallel redundant UPS. Telecommun Energy Conf 2003:493-8.

[13] Tsai-Fu W, Yu-Kai C. 3C strategy for inverters in parallel operation achieving an equal current distribution. IEEE Trans Ind Elect 2000;7(2):273-81.

[14] Siri K, Lee CQ, Wu TF. Current distribution control schemes for parallel connected converter modules, Part II: Central-limit control. IEEE Trans Aerosp Electron Syst 1992;28:841-51.

[15] Yu-Kai C, Yu-En W. ACSS for paralleled multi-inverter systems with DSP based robust controls. IEEE Trans Aerosp Electr Syst 2003;9(3):1002-15.

[16] Siri K, Wu TF, Lee CQ. Current distribution control schemes for parallel connected converter modules, Part I: Master-slave control. IEEE Trans Aerosp Electron Syst 1992;28:829-40.

[17] Pei Y, Jiang G, Yang X, Wang Z. Auto-master-slave control technique of parallel inverters in distributed AC power systems and UPS. IEEE PES Conf 2004;3:2050-3.

[18] Shanxu D, Yu M, Jian X, Yong K, Jian C. Parallel operation control technique of voltage source inverters in UPS. Power Electron Drive Syst Conf 1999:883-7.

[19] Sun X, Lee YS, Xu D. Modelling, analysis, and implementation of parallel multi-inverter system with instantaneous average-current-sharing scheme. IEEE Trans Power Electron 2003;18(3):844-56.

[20] Cheng YJ, Sng EKK. A novel communication strategy for decentralized control of paralleled multi-inverter systems. IEEE Trans Power Electron 2006;21(1):148-56.

[21] Tao J, Lin H, Zhang J, Ying J. A novel load sharing control technique for paralleled inverters. IEEE PES Conf 2003:1432-7.

[22] Ching-Tsai P, Yi-Hung L. Modelling and control of circulating currents for parallel three-phase boost rectifiers with different load sharing. IEEE Trans Ind Electron 2008;5(7):2776-85.

[23] Chandorkar MC, Divan DM, Adapa R. Control of parallel connected inverters in standalone ac supply systems. IEEE Trans Ind Appl 1993;29:136-43.

[24] Tuladhar A, Jin H, Unger T, Mauch K. Parallel operation of single phase inverters with no control interconnections. IEEE APEC 1997:94-100.

[25] Tuladhar A, Unger HJT, Mauch K. Control of parallel inverters in distributed AC power systems with consideration of line impedance effect. IEEE Trans Ind Appl 2000;6(1):131-8.

[26] Guerrero JM, Hang L. Control of distributed uninterruptible power supply systems. IEEE Trans Ind Electron 2008;5(8):2845-59.

[27] Guerrero JM, de Vicuna LG. A wireless controller to enhance dynamic performance of parallel inverters in distributed generation systems. IEEE Trans Power Electron 2004;9(5):1205-13.
[28] Guerrero JM, Matas MJ. Wireless-control strategy for parallel operation of distributed-generation inverters. IEEE Trans Ind Electron 2006;3(5):1461-70.

[29] De Brabandere, Bolsens B. A voltage and frequency droop control method for parallel inverters. IEEE Trans Power Electron 2007;2(4):1107-15.

[30] Marwali MN, Jin-Woo J. Stability analysis of load sharing control for distributed generation systems. IEEE Trans Energy Convers 2007;2(3):737-45.

[31] Sao CK, Peter PW. Control and power management of converter fed microgrids. IEEE Trans Power Systems 2008;23(3):1088-98.

[32] Parlak KS, Özdemir SM. Active and reactive power sharing and frequency restoration in a distributed power system consisting of two UPS units. Int J Electr Power Energy Syst 2009;31(5):220-6.

[33] Marwali MN. Control of distributed generation systems - Part I: Voltages and Currents control. IEEE Trans Power Electron 2004;9(6):1541-50.

[34] Marwali MN, Jin-Woo J. Control of distributed generation systems - Part II: Load sharing control. IEEE Trans Power Electron 2004;9(6):1551-61.

[35] Marwali MN, Dai M, Keyhani A. Robust stability analysis of voltage and current control for distributed generation systems. IEEE Trans Energy Convers 2006;1(2):516-26.

[36] Guerrero JM, de Vicuña LG, Matas J, Castilla M, Miret J. Output impedance design of parallel-connected UPS inverters with wireless load-sharing control. IEEE Trans Ind Electron 2005;52(4):1126-35.

[37] Corradini L, Corradin M, Mattavelli P, Polo F. Analysis of parallel operation of uninterruptible power supplies loaded through long wiring cables. IEEE Trans Power Electron 2010.

[38] Vasquez JC, Guerrero JM, Luna A, Rodriguez P, Teodorescu R. Adaptive droop control applied to voltage-source inverters operating in grid-connected and islanded modes. IEEE Trans Ind Electron 2009;56(10):4088-96.

[39] Majumder R, Ghosh A, Ledwich G, Zare F. Load sharing and power quality enhanced operation of a distributed microgrid. IET Renew Power Gen 2009;3(2):109-19.

[40] Majumder R, Chaudhuri B, Ghosh A, Majumder R, Ledwich G, Zare F. Improvement of stability and load sharing in an autonomous microgrid using supplementary droop control loop. IEEE Trans Power Syst 2010.

[41] Yang C, Smedley KM. One-cycle-controlled three-phase grid-connected inverters and their parallel operation. IEEE Trans Ind Appl 2008;4(2):663-71.

[42] Zhang Z, Huang X. A load-sharing control scheme for a microgrid with a fixed frequency inverter. Electr Power Syst Res 2010;80(3):311-7.

[43] Chiang SJ, Chang JM. Design and implementation of the parallel able active power filter. IEEE PES Conf 1999;1:406-11.

[44] Chiang SJ, Chang JM. Parallel operation of shunt active power filters with capacity limitation control. IEEE Trans Aerosp Electron Syst 2001;37(4): 1312-20.

[45] Abdelli Y, Machoum M, Khoor MS. Control of a multimodule parallel able threephase active power filters. Int Conf Harmonics Qual Power 2004:543-8.

[46] dos Santos EC, Jacobina CB, Maciel AM. Parallel connection of two shunt active power filters with losses optimization. APEC 2010;1:1191-6.

[47] Surgevil T, Vardar K, Akpnar E. Analysis of shunt active power filters using PSCAD for parallel operation; 2009. p. 263-7.

[48] Akagi H, Nabae K. Control strategy of active power filters using multiple voltage source PWM converters. IEEE Trans Ind Appl 1985;1(3):460-6.

[49] Asiminoaei L, Aeloiza E, Kim J, Enjeti PH, Blaabjerg F, Moran L, Sul S. Parallel interleaved inverters for reactive power and harmonic compensation, PESC 2006. p. 1-7.

[50] Wei X, Dai K, Fang X, Geng P, Luo F, Kang Y. Parallel control of three-phase three-wire shunt active power filters. IPEMC 2006;2:1-5.

[51] Pregitzer R, Pinto J, Sepulveda G, Joao M, Fonso A, Joao L. Parallel association of shunt active power filters. ISIE 2007:2493-8.

[52] Mattavelli P. A closed-loop selective harmonic compensation for active filters IEEE Trans Ind Appl 2001;37(1):81-9.

[53] Asiminoaei L, Lascu C. Performance improvement of shunt active power filter with dual parallel topology. IEEE Trans Power Electron 2007;2(1):247-59.

[54] Akagi H, Fujita H, Wada K. A shunt active filter based on voltage detection for harmonic termination of a radial power distribution line. IEEE Trans Ind Appl 1999;35(3):638-45.

[55] Wada K, Fujita H, Akagi H. Considerations of a shunt active filter based on voltage detection for installation on a long distribution feeder. IEEE Trans Ind Appl 2002;38(4):1123-30.

[56] Jintakosonwit P, Akagi H, Fujita H, Ogasawara S. Implementation and performance of automatic gain adjustment in a shunt active filter for harmonic damping throughout a power distribution system. IEEE Trans Power Electron 2002;17(3):438-47.

[57] Jintakosonwit P, Fujita H, Akagi H, Ogasawara S. Implementation and performance of cooperative control of shunt active filters for harmonic damping throughout a power distribution system. IEEE Trans Ind Appl 2003;39(2):556-64

[58] Cheng P-T, Lee T-L. Distributed active filter systems (DAFSs): a new approach to power system harmonics. IEEE Trans Ind Appl 2006;2(5):1301-9.

[59] Lee T-L, Cheng P-T, Akagi H, Fujita H. A dynamic tuning method for distributed active filter systems. IEEE Trans Ind Appl 2008;4(2):612-23.

[60] Falahi G, Mokhtari H. Performance improvement of parallel active power filters using droop control method. APPEEC 2009:1-4.

[61] Borup U, Blaabjerg F, Enjeti PN. Sharing of nonlinear load in parallel-connected three-phase converters. IEEE Trans Ind Appl 2001;37(6):1817-23. 